\title{
Novel Tools and Investigative Approaches for the Study of Oligodendrocyte Precursor Cells (NG2-Glia) in CNS Development and Disease
}

\author{
Christophe Galichet*, Richard W. Clayton and Robin Lovell-Badge \\ Laboratory of Stem Cell Biology and Developmental Genetics, The Francis Crick Institute, London, United Kingdom
}

\section{OPEN ACCESS}

Edited by:

Francesca Boscia,

University of Naples Federico II, Italy

Reviewed by:

Moritz Rossner,

Ludwig Maximilian University of

Munich, Germany

Davide Lecca,

University of Milan, Italy

Akiko Nishiyama,

University of Connecticut,

United States

*Correspondence:

Christophe Galichet

christophe.galichet@crick.ac.uk https://orcid.org/0000-0002-2497-

2942

Specialty section: This article was submitted to

Non-Neuronal Cells,

a section of the journal

Frontiers in Cellular Neuroscience

Received: 26 February 2021 Accepted: 07 April 2021

Published: 29 April 2021

Citation:

Galichet C, Clayton RW and Lovell-Badge $R$ (2021) Novel Tools and Investigative Approaches for the Study of Oligodendrocyte Precursor Cells (NG2-Glia) in CNS Development

and Disease.

Front. Cell. Neurosci. 15:673132. doi: 10.3389/fncel.2021.673132
Oligodendrocyte progenitor cells (OPCs), also referred to as NG2-glia, are the most proliferative cell type in the adult central nervous system. While the primary role of OPCs is to serve as progenitors for oligodendrocytes, in recent years, it has become increasingly clear that OPCs fulfil a number of other functions. Indeed, independent of their role as stem cells, it is evident that OPCs can regulate the metabolic environment, directly interact with and modulate neuronal function, maintain the blood brain barrier (BBB) and regulate inflammation. In this review article, we discuss the state-of-the-art tools and investigative approaches being used to characterize the biology and function of OPCs. From functional genetic investigation to single cell sequencing and from lineage tracing to functional imaging, we discuss the important discoveries uncovered by these techniques, such as functional and spatial OPC heterogeneity, novel OPC marker genes, the interaction of OPCs with other cells types, and how OPCs integrate and respond to signals from neighboring cells. Finally, we review the use of in vitro assay to assess OPC functions. These methodologies promise to lead to ever greater understanding of this enigmatic cell type, which in turn will shed light on the pathogenesis and potential treatment strategies for a number of diseases, such as multiple sclerosis (MS) and gliomas.

Keywords: oligodendrocyte precursor cells, NG2-glia, heterogeneity, imaging, sequencing, genetic alteration

\section{INTRODUCTION}

Oligodendrocytes (OLs) are the myelin-producing cells of the central nervous system (CNS) and play an essential role in facilitating neuronal signal conduction. OLs are the most numerous of the various types of glial cell in the adult mouse brain, representing approximately $20 \%$ of all brain cells (Valério-Gomes et al., 2018), and while OLs can be found throughout the entire CNS, they are most abundant in white matter tracts (Valério-Gomes et al., 2018). OLs are derived from precursor cells that can be defined by expression of the proteoglycan NG2, neuron-glial antigen 2 (also known as CSPG4, Chondroitin Sulfate Proteoglycan 4; Figure 1). These progenitor cells are therefore frequently referred to as "NG2-glia," but this term is often used interchangeably with that of "oligodendrocyte precursor cells" (OPCs), which we will use throughout this review article. 
The process of oligodendrocyte lineage differentiation from OPCs, to pre-OLs, maturing OLs, and finally, fully mature OLs, has been well delineated, with many underlying transcription factors and signaling pathways having been shown to play a role (Figure 1; for review: Elbaz and Popko, 2019; Kuhn et al., 2019). In mice, the majority of OLs are generated within the first 4 weeks of post-natal life. However, generation of new OLs continues throughout adulthood (Rivers et al., 2008; Kang et al., 2010; Zhu et al., 2011), although this process declines with age, and is influenced by environmental factors such as daylight or physical exercise (for review: Wang and Young, 2014). Many excellent reviews have already extensively covered the subject of OL development (Bergles and Richardson, 2015; Traiffort et al., 2016; Elbaz and Popko, 2019; Kuhn et al., 2019; Boshans et al., 2020).

Similar to OLs, OPCs are located throughout the CNS. In the adult brain, OPCs represent approximately $5-10 \%$ of all brain cells, and are the most proliferative cell type (Dawson et al., 2000, 2003). This proliferative behavior makes OPCs especially sensitive to experimental manipulations of the cell cycle (Djogo et al., 2016). Subtypes of OPCs have been described according to various parameters, such as their spatial relation to the brain's vasculature: e.g., perivascular, parenchymal, and intermediate (Seo et al., 2014; Maki et al., 2015; Kishida et al., 2019), whether they are located in white or gray matter, or according to the differential expression of receptors and ion channels (Spitzer et al., 2019). Morphologically, OPCs have small, rounded cell bodies $(10-15 \mu \mathrm{m})$ and exhibit extensive branching processes. In gray matter, these processes spread out from the OPC cell body in a radial manner, whereas in white matter, they are more longitudinally orientated, following the path of axons in tracts of white matter (Levine et al., 2001). The full extent of the potential morphological, functional and molecular heterogeneity of OPCs remains unclear, as does the importance of different subsets of OPCs to brain function and disease (Zong et al., 2015; Duncan and Radcliff, 2016).

Outside of their role as progenitor cells for OLs, recent evidence has demonstrated that OPCs may have additional functions, such as interacting with other cell types and modulating their function. For example, not only do OPCs receive synaptic input from both excitatory and inhibitory neurons (Bergles et al., 2000; Lin and Bergles, 2004; VélezFort et al., 2010; Nagy et al., 2017), they also synthesize neuromodulatory factors such as prostaglandins D2 synthetase and neuronal pentrazin 2 (Sakry et al., 2015). NG2 proteoglycan, the stereotypical marker of OPCs, has itself been shown to modulate NMDA-dependent long-term potentiation and AMPA receptor sub-unit composition in excitatory neurons (Sakry et al., 2014). Moreover, targeted ablation of OPCs results in deficits in glutamatergic neurotransmission (Birey et al., 2015).

OPCs also receive inhibitory neuronal input (Lin and Bergles, 2004; Kukley et al., 2008), which, at least in the mouse cerebellum, is mediated through $\mathrm{GABA}_{\mathrm{A}}$ receptors (Labrada-Moncada et al., 2020); however the functional consequence of this interaction remains unclear.

OPCs also interact with other non-neuronal cell types including astrocytes, which themselves have many roles, such

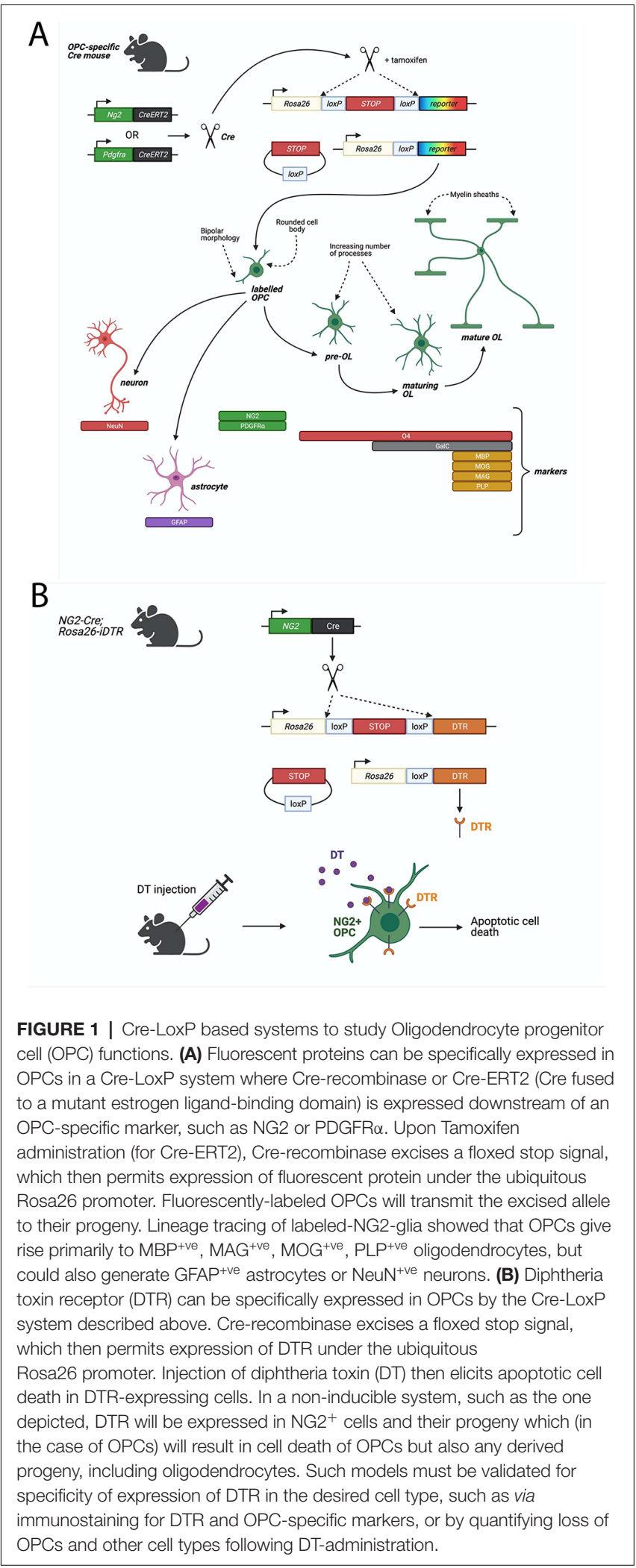

as supporting and modulating neuronal function, or from regulating cerebral blood flow to maintaining the blood brain barrier (BBB; for review: Nutma et al., 2020) and microglia, which 
can be considered the immune cells of the CNS (for review: Domingues et al., 2016). Altogether, these findings indicate the existence and functional importance of bi-directional crosstalk between OPCs, neurons, and other cell types, and have shed light on the extent to which normal function of the adult brain may be dependent on OPCs.

It is becoming increasingly clear that OPCs are of great clinical importance, and understanding their biology and function is a prerequisite to understanding their potential role in various diseases. For example, many conditions are associated with defective myelination, such as multiple sclerosis (MS) (MS, an auto-immune disease that results in the destruction of myelin), Devic's disease (where inflammation results in subsequent demyelination of the CNS) or exposure to chemical toxins that directly affect myelin and/or OLs (for review: Duncan and Radcliff, 2016). The formation of gliomas, including oligodendrogliomas, implicates OPCs as they represent a potential cell type from which these tumors can originate (for review: Zong et al., 2015), and the functional interaction of OPCs with neurons and other cell types may indicate their relevance for a wide range of other conditions, for example, hypopituitarism or depression (Birey et al., 2015; Djogo et al., 2016).

In recent years, our understanding of different OPC functions and characteristics has greatly expanded, and several excellent reviews have highlighted this (Dawson et al., 2000; Levine et al., 2001; Dimou and Gallo, 2015; Domingues et al., 2016; Eugenín-Von Bernhardi and Dimou, 2016; Foerster et al., 2019; Kuhn et al., 2019; Hirbec et al., 2020). In this review article, we focus our discussion on both established and novel tools and approaches that can be used to investigate the roles of OPCs in the developing and adult brain. We cover functional approaches, including use of various transgenic mice and experimental treatments, transcriptomic techniques, available imaging methodologies and physiological approaches such as electrophysiology and optogenetics, and we also discuss the multitude of culture systems used to generate and maintain OPCs in vitro, including $2 \mathrm{D}$ and $3 \mathrm{D}$ techniques, using primary animal or human cell lines or OPCs derived from induced pluripotent stem cells.

\section{GENETIC TECHNOLOGIES}

\section{Functional Genetics}

The use of genetically altered animals offers several advantages compared to in vitro experiments, such as being able to study the functions of genes in an endogenous environment, with full interplay between different organ systems. Nevertheless, in vitro methods, which are described later in the review, bring invaluable data that often cannot be achieved using animal models. Functional genetic approaches, have revealed both intrinsic and extrinsic factors associated with different stages of OPC development; from initiation, proliferation, and maintenance to differentiation into pre-myelinating OLs and subsequently myelinating OLs (Bergles and Richardson, 2015; Elbaz and Popko, 2019; Boshans et al., 2020). For example, the use of transgenes expressing extrinsic factors have shown how several secreted factors regulate this process, including plateletderived growth factor (PDGF; Woodruff et al., 2004), and thyroid hormone (Ahlgren et al., 1997). More recently, progesterone has been shown to up-regulate expression of NG2, PDGFR $\alpha$ and Sox9 (González-Orozco et al., 2020). OPC-derived interleukin-33 (IL-33) has also been shown to regulate the differentiation of OLs to mature OLs in vitro, by lentivirus-mediated knock-down experiments resulting in a down-regulation of OL differentiation genes, and in vivo, by analyzing $I L-33$ null mice which revealed defective myelination in the corpus callosum (Sung et al., 2019). Cells of the OPC lineage are also influenced by other systemic or environmental changes (ageing, inflammation or hypoxia; for review: Baydyuk et al., 2020). Extrinsic factors also include different cell types with which cells of the OPC lineage are in contact (neurons, astrocytes, blood vessels and microglia), some of which were manipulated by genetic alteration while other evidence came from co-culture in vitro experiments (for review: Baydyuk et al., 2020).

An especially informative genetic approach involves conditional expression of diphtheria toxin (DT) receptor (iDTR), enabling targeted ablation of OPCs in the adult mouse brain. Expression of Cre-inducible iDTR in NG2-expressing cells has allowed for the targeted induction of cell death in OPCs following DT administration (Figure 1; Birey et al., 2015; Zhang S.-Z. et al., 2019; Liu and Aguzzi, 2020). By this method, tissue-specific ablation of OPCs in the mouse prefrontal cortex was achieved by delivering DT via a cannula implanted into the targeted brain region, with the result of causing depressive-like behaviors, indicated by reduced open field activity (Birey et al., 2015). It was subsequently found that this loss of OPCs leads to deficits in glutamatergic neurotransmission as well as in extracellular glutamate uptake by astrocytes (Birey et al., 2015).

Similar studies, again using DT-mediated ablation of NG2-expressing cells, have provided the first indications of a role of OPCs in the maintenance of brain immune homeostasis and, while it has been known for some time that microglia can regulate the behavior and differentiation of OPCs (reviewed by Domingues et al., 2016), these studies have shown that OPCs can, in turn, modulate microglia (Zhang S.-Z. et al., 2019; Liu and Aguzzi, 2020; Marsters et al., 2020; Mecha et al., 2020). In the absence of NG2-positive OPCs, microglia become hypersensitive to lipopolysaccharide (LPS) injection, resulting in microglial activation and neuroinflammation (Zhang S.-Z. et al., 2019). OPC-derived TGF- $\beta 2$ was subsequently shown to suppress microglial activation in vitro (Zhang S.-Z. et al., 2019). Building on this work, a more recent study has shown that, following ablation of OPCs in vivo, using the described DT methods in PdgfR $\alpha^{\text {CreERT }}$ mice (Liu and Aguzzi, 2020), there is a whole-brain reduction in the expression of genes associated with microglial homeostasis (such as Tmem119 and Olfml3). Similar effects on microglial gene expression can be observed using Crenolanib (a PDGFR inhibitor) in mouse brain slice cultures, which has the effect of depleting OPCs (Liu and Aguzzi, 2020). Finally, this role of microglial-OPC crosstalk has also been highlighted in the development of the hypothalamus (Marsters et al., 2020). 
Depletion of microglia, achieved by administering PLX5622, an antagonist of the receptor for the microglia-stimulating CSF1, results in decreased OPC migration to the mantle zone in the embryonic hypothalamus; a result which likely arises due to the lack of microglia-secreted cytokines (Marsters et al., 2020). Intriguingly, it is also possible that OPCs directly fulfill immune cell-associated functions, such as tissue remodeling and regulating blood vessel permeability. For example, in a mouse model of prolonged cerebral hypoperfusion, OPCs are the first cell type to produce matrix metallopeptidase 9 (MMP-9), an enzyme which degrades the extracellular matrix. Expression of MMP9 was shown to facilitate infiltration of neutrophils beyond the blood brain barrier (BBB), suggesting that OPCs may contribute to pathological neuroinflammation (Seo et al., 2013). Moreover, under certain conditions, OPCs express inflammatory cytokines such as IL-1ß or CCL-2, which are implicated in recruiting monocytes (Deshmane et al., 2009; Moyon et al., 2015). Some studies have also indicated that OPCs may be the cell of origin in gliomas/glioblastomas (Zong et al., 2015). While adult mouse OPCs were transformed by mutation of $p 53$ and NF1 in vivo using NG2-CreER, which led to formation of malignant gliomas (Galvao et al., 2014), much of the molecular mechanism remains unknown.

More conventional gene mutation studies have also been instrumental in dissecting out components of OPC biology. For example, building on the potential role of OPCs in regulating the status of the BBB, tissue-specific ablation of TGF- $\beta 1$ in mice (Pdgfr $\left.\alpha-C r e ; \mathrm{Tgfb}^{f l o x}\right)$ resulted in loss of BBB function and cerebral hemorrhage (Seo et al., 2014). Other work has further refined the function of OPC-neuronal crosstalk, as previously discussed (Birey et al., 2015; Labrada-Moncada et al., 2020). From such studies, we know that OPCs express ion-channels and neurotransmitter receptors which allow them to detect neuronal activity (Larson et al., 2016) and, in turn, modulate neuronal behavior (Wang and Young, 2014; Douglas Fields, 2015; Purger et al., 2016). To give an example, the voltagegated calcium channel (CaV1.2; Haberlandt et al., 2011) has been shown to be a major channel for depolarization-induced calcium entry in OPCs (Cheli et al., 2015, 2016). Conditional deletion of CaV1.2 within OPCs results in impaired myelination during postnatal mouse development (Cheli et al., 2016), as well as reduced reactive remyelination in a mouse model of chemically-induced demyelination (Santiago González et al., 2017). Interestingly, while studies with genetically altered mice have shown that CaV1.2 is essential for OPC survival in the adult mouse corpus callosum, it is dispensable in the motor cortex or spinal cord (Pitman et al., 2020) indicating regional heterogeneity, at least in the case of a reliance of OPCs on specific ion channels. Other conditional mutation studies have, for example, demonstrated the importance of iron storage proteins for OPC development and differentiation (Wan et al., 2020), as well as shown that Golli proteins (derivatives of the myelin basic protein gene complex) facilitate OPC migration during development by promoting $\mathrm{Ca}^{2+}$ transient currents in OPCs (Paez et al., 2009).

Finally, instigation of local disturbances in OPC function, through virus-mediated gene expression, has further illuminated the functional nature of neuronal-OPC crosstalk. Depending on the type of viruses used, these offer distinct approaches from affecting only dividing cells, to integrating the genetic information into the host genome, or only allowing for transient expression (Kamimura et al., 2011). For example, it is known that OPCs express AMPA receptors, activation of which by neuronal glutamate leads to OPC depolarization (Bergles et al., 2000). Retroviral delivery of various forms of modified AMPA-R GluA2 subunit to early postnatal animals (when the rate of OPC proliferation is highest; Moshrefi-Ravasdjani et al., 2017) reveals that both ionotropic and non-ionotropic properties of AMPA-R are essential for regulating the balance between OPC proliferation and differentiation (Chen et al., 2018). For example, forcible expression of a $\mathrm{Ca} 2^{+}$-permeable AMPA-Rs in OPCs results in increased proliferation at the expense of differentiation into myelinating OLs (Chen et al., 2018). Non-virus mediated gene expression methods can also be used, such as transfection with cationic polymer or magnetofection, however, these methods currently only show low expression efficiencies (Kamimura et al., 2011).

\section{Lineage Tracing and Fate Mapping}

Genetically-inducible fate mapping (lineage tracing allowing to follow labeled cell and their progeny) techniques have been used to study OPCs and their subsequent lineages for decades, and have made it possible to characterize and fate-map OPCs and their progeny. In embryonic mouse brains, lineage tracing experiments have demonstrated that the generation of OPCs follows a ventral-to-dorsal "Mexican wave" (Kessaris et al., 2006). While the majority of OPCs will generate OLs, recent studies have also indicated that OPCs may be capable of forming neurons and astrocytes (Rivers et al., 2008; Zhu et al., 2008a,b; Guo et al., 2010; Robins et al., 2013). Using NG2-Cre transgenic animals, NG2-positive OPCs were shown to generate a subpopulation of protoplasmic astrocytes in the gray matter of both the ventrolateral forebrain and spinal cord, but they did not form white matter astrocytes (Zhu et al., 2008a,b). More recent studies have demonstrated that OPCs are able to generate neurons in the adult hypothalamus, using NG2-CreER transgenic mice (Robins et al., 2013), and in the cortex, using PLP-Cre ${ }^{E R T}$ (Guo et al., 2010) or $P d g f R \alpha-C r e^{E R T 2}$ mice (Rivers et al., 2008). The latter is still subject to debate, because subsequent work has indicated that OPCs do not generate cortical neurons (Kang et al., 2010; Zhu et al., 2011; Clarke et al., 2012). However, using $N G 2^{C r E E R T 2}$ mice, it has been shown that postnatal OPCs can generate at least some cortical neurons (Huang et al., 2014), while embryonic OPCs are exclusively gliogenic, with derivatives restricted mainly to the OL lineage, apart from a small amount of astrocyte production in the ventral forebrain (Huang et al., 2019). Tools have also been generated to study the organization and development of the OPC lineage network at single-cell resolution, notably using PLP-CreERT2 combined with the Brainbow system (Dumas et al., 2015). This method makes it possible to distinguish individual cells from their neighbors using multiple fluorescent proteins activated at random via the Cre/LoxP system, and further allows studies into the clonal dynamics of OPC development. 
In order to characterize which neurons make direct connections to OPCs, monosynaptic tracing methods can be employed. For example, PDGFR $\alpha$-CreER mice have been used to conditionally express the rabies virus glycoprotein 4 (gp4) and the avian TVA receptor, the receptor for subgroup A avian leukosis viruses, in OPCs. Following tamoxifen administration, gp4-deleted rabies viruses encoding GFP are stereotaxically administered to different brain regions (corpus callosum, premotor cortex). As they express the missing viral component for infection, only OPCs are infected by gp4-deleted virus allowing a monosynaptic transmission of OPC inputs to first, but not higher orders of connected cells. This revealed that corpus callosum OPCs receive brain-wide synaptic inputs both from excitatory and inhibitory neurons (Mount et al., 2019).

An important technical consideration regarding NG2- or PdgfR $\alpha$-based lineage tracing of OPCs (and indeed, of any functional genetic approaches using the same gene drivers), is that NG2 and PdgfR $\alpha$ are also expressed by certain other cell types. These include pericytes, cells which enwrap the vasculature of the brain (Ozerdem et al., 2001), or a sub-population of adult sub-ependymal zone (SEZ) B cells and non-vascular meningeal cells (Jackson et al., 2006; Andrae et al., 2016) respectively. Lineage tracing experiments using NG2-CreBAC and $N G 2^{C r E E R T 2}$ mice may therefore encompass pericytes and any cell that is derived from them. Of course, consideration must also be given to the fact that transgenic animals may not necessarily fully reflect endogenous gene expression and/or may have ectopic expression (for review: Bouabe and Okkenhaug, 2013). One study has used a dual-promoter approach to more selectively target pericytes rather than OPCs, by requiring both expression of Pdgfrb and NG2 for induction of Cre-mediated recombination (Nikolakopoulou et al., 2019). A similar approach could conceivably be used to better target and label OPCs based on the expression of multiple markers, especially given the recent studies characterizing the OPC transcriptome, which could be further interrogated to reveal novel OPC marker genes (Marques et al., 2018; Elbaz and Popko, 2019).

\section{Irradiation and Cell-Cycle Disruption}

As mentioned above, OPCs are the most proliferative cell type in the brain (Dawson et al., 2000, 2003). OPCs are therefore especially susceptible to cell cycle disruption, and to cell death induced as a result of DNA damage checkpoints during the cell cycle (Borges et al., 2008). Consequently, inducing DNA damage through external factors [e.g., by irradiation or administration of the mitotic blocker cytosine- $\beta$-D-arabinofuranoside (Ara-C)] or genetically in the brain has the effect of predominantly affecting OPCs (Chari and Blakemore, 2002; Irvine and Blakemore, 2007; Robins et al., 2013; Djogo et al., 2016). Used concomitantly with tissue specific gene drivers, such experiments can achieve very specific ablation of OPCs. For example, Djogo et al. (2016) employed such methods to ablate NG2-glia within the hypothalamus, including $\mathrm{AraC}$ administration via the third ventricle, X-irradiation, and genetic ablation using Sox10iCreERT2 to delete Esco2 (a necessary cell cycle gene). Together, these techniques demonstrated the importance of OPCs in maintaining leptin receptor-expressing neuronal processes and regulating feeding behaviors in mice. Another approach has been the use of the suicide gene herpes simplex virus thymidine kinase (HSVtk), expressed under the control of the NG2 promoter in rats. Upon ganciclovir administration, dividing HSVtkexpressing OPCs are selectively ablated leading to impaired hippocampal neuronal functions and increased inflammation (Nakano et al., 2017). Similarly, NG2-tk mice have been generated to ablate NG2-positive pericytes and OPCs in the context of spinal cord injury, leading to altered astrocytic responses and recovery (Hesp et al., 2018).

The genetic techniques discussed above have been instrumental in building our current understanding of OPC biology. However, in order to further advance the boundaries of the field, more recent techniques seeking to examine OPC transcriptomes and metabolomes have begun to uncover the extent of OPC heterogeneity, and to identify novel OPC markers and potential genes for further mechanistic investigation.

\section{TRANSCRIPTOMIC TECHNOLOGIES}

The different potential functions of OPCs have begun to be revealed by mutation studies and by using techniques for genetic ablation and lineage tracing, as described. However, such advances are greatly supplemented by genome-wide transcriptomic analyses, which have become powerful investigative tools in their own right (Hwang et al., 2018). Indeed, the generation of global gene expression/regulatory networks through bulk RNA sequencing (RNA-seq) or single cell approaches has greatly refined our understanding of the biology of OPCs and OLs (Figure 2). Techniques such as single cell or single nucleus RNA sequencing (scRNA-seq and snRNA-seq respectively), where the latter allows profiling from frozen tissues or when fresh tissue dissociation is unsuccessful, while the former gives higher amounts of mRNA (Habib et al., 2017), as well as sequencing of open chromatin, which generally reflects areas of active gene expression or active enhancer regions, by Assay for Transposase-Accessible Chromatin (ATAC-seq), have been crucial in uncovering marker profiles of OPCs (Marques et al., 2018), identifying important regulatory genes and gene networks in OPC differentiation (for review: Elbaz and Popko, 2019). These sequencing methodologies have also delineated heterogeneity amongst OPC and OL populations in both spatial and temporal contexts (Marques et al., 2016, 2018; Beiter et al., 2020).

Indeed, a prevailing question that these transcriptomic techniques has begun to answer is whether OPCs and OLs represent homogenous populations, or whether they exist in functionally and transcriptomically distinct subgroups. Pioneering work, using microarray systems and bulk RNA-seq, has revealed the molecular signatures of many different cell types in the brain, including OPCs and oligodendrocytes (Cahoy et al., 2008; Zhang et al., 2014). The first study to focus exclusively on gene expression in OPCs was conducted in a mouse model of demyelination (Moyon et al., 2015). In this study, OPCs were purified through FACS, using brains from PdgfR $\alpha-G F P$ mice at either the neonatal stage, in 2-month old adults, or adult mice that had been treated with cuprizone for 5 weeks. 
Transcriptomic differences were then analyzed by microarray, and early neonatal and adult OPCs were found to differ in the expression of markers of OL differentiation, with adult OPCs having a transcriptome more akin to that of OLs than that of neonatal OPCs (Moyon et al., 2015). Interestingly, in demyelination conditions elicited by cuprizone treatment, adult OPCs reverted to a more neonatal and relatively undifferentiated state (Moyon et al., 2015).

Subsequent work has confirmed the existence of this temporal heterogeneity between OPCs in the juvenile and adult mouse brain, and further indicated that transcriptional homogeneity in the juvenile brain gives way to transcriptional divergence in the adult, which may or may not reflect regional differences (Marques et al., 2016, 2018; Beiter et al., 2020). By using flow cytometry to isolate OPCs in PdgfRa-H2B-GFP or PdgfRaCreERT mice, followed by bulk RNA-seq and scRNA-seq, different embryonic stages were associated with district gene expression profiles that reflect the regional and temporal patterns of OPC generation. Interestingly, there appears to be a convergence of gene expression in early postnatal OPCs (Marques et al., 2018), while in the different clusters identified in adult mice, some were not specific to the OL lineage, such as fibroblasts, endothelial cells, pericytes, and leptomeningeal cells (Marques et al., 2016; Beiter et al., 2020). In the adult, OPC-specific clusters, on further investigation, were also found to be heterogenous, with genes like Gpr17 and Clusterin representing novel markers of different OPC populations (Beiter et al., 2020). Furthermore, sex-specific differences in the composition of heterogenous OPC populations within specific brain regions has been recently noted, although the varieties of OPCs present throughout the brain do not appear to be different between sexes (Beiter et al., 2020). Finally, a recent study has translated these findings to humans, where scRNA-seq revealed in humans that fetal, pediatric and adult OPCs have distinct transcriptomes (Perlman et al., 2020). Furthermore, OPC diversity seems to become more pronounced over time, at least in mice (Spitzer et al., 2019).

While these data provide a valuable insight into OPC heterogeneity in the adult brain, it remains unclear whether there is a correlation between regional and functional differences in OPCs, in other words, asking whether OPCs from distinct brain regions function differently. Previous studies that targeted their scRNA-seq characterization to specific brain regions have not so far described any heterogeneity in OPCs, although it is worth noting that these studies did not focus on OPCs exclusively (Zeisel et al., 2015; Habib et al., 2016; Tasic et al., 2016; Chen et al., 2017). More recently, bulk RNA-seq of magnetic activated cell sorted (MACS) OPCs revealed that OPCs become regionally diverse with age, with respect to their expression of particular ion channels and sensitivity to neuronal activity (Spitzer et al., 2019). Since then, two molecularly distinct OPC populations have been described in the adult suprachiasmatic nucleus, but no further characterization has yet been undertaken (Wen et al., 2020). In the embryonic zebrafish spinal cord, at least two spatially and functionally distinct OPC subgroups have been described: one population that migrates laterally and generates myelinating OLs, and another that regulates neuronal excitability (Marisca et al., 2020). Furthermore, novel transcriptomic methods such as spatial transcriptomics could be used to perform scRNA-seq in tissue sections, potentially leading to the identification of uncharacterized OPC sub-groups in different anatomical regions (Figure 2; Ståhl et al., 2016).

OPC heterogeneity has also been demonstrated regarding their responses to growth factors and cytokines. For example, gray and white matter-derived OPCs respond differently to INF $\gamma$ in terms of their proliferation, differentiation and process arborization (Lentferink et al., 2018), and to PDGF in terms of their proliferation (Hill et al., 2013). Furthermore, subpopulations of adult white matter OPCs differentially respond to growth factor (PDGF-AA, IGF-1 and FGF-2) and display differential gene expression patterns (Mason and Goldman, 2002; Lin et al., 2009). In summary, RNA sequencing of adult OPCs have revealed that they are a heterogeneous population of many different cells whose individual functions remain unknown.

The changing chromatin landscape has also been analyzed during OPC differentiation (Castelo-Branco and Liu, 2020) and mutations in chromatin modifiers, such as CHD7 and CHD8, have a profound effect on the formation of OLs from OPCs (Marie et al., 2018). Given the now widespread appreciation of the relationship between chromatin status and differentiation in multiple tissues (for example in skeletal muscle; HernándezHernández et al., 2020), this is not a surprising finding, but it nevertheless underscores epigenetic regulation as another field of ongoing research regarding OPCs (Gregath and Lu, 2018).

Finally, while transcriptomic studies yield invaluable information about the RNA contents of specific cells, proteomics are essential in correlating transcription with actual protein expression (Vidova and Spacil, 2017). In one study, large numbers of rat OPCs were cultured and differentiated in vitro. The proteomic profile of these cells was then analyzed at different time points throughout differentiation. Quantitative expression data was subsequently obtained for 5,259 proteins, revealing distinct patterns of regulation. Such techniques could also be used for novel candidate protein identification (Schoor et al., 2019).

Altogether, these studies indicate that, by global or local functional genetic approaches and transcriptional analysis, valuable information arises about the crosstalk between OPCs and their neighboring cells. Such information should be put in the context in which the cells are found, namely their physical interactions with their neighbors and their anatomical location. Furthermore, as OPCs are precursor cells, understanding their fate in relation to their heterogeneity will be crucial, for example, it may be that one subpopulation of OPCs is more likely to differentiate than others. Imaging techniques, including lineage tracing, are powerful tools to begin tackling these questions.

\section{IMAGING AND MICROSCOPIC TECHNIQUES}

Oligodendrocytes and OPCs, like many of the different cell types in the brain, have a complex, branched morphology and reside in a substantial three-dimensional volume (Ono et al., 2001). 


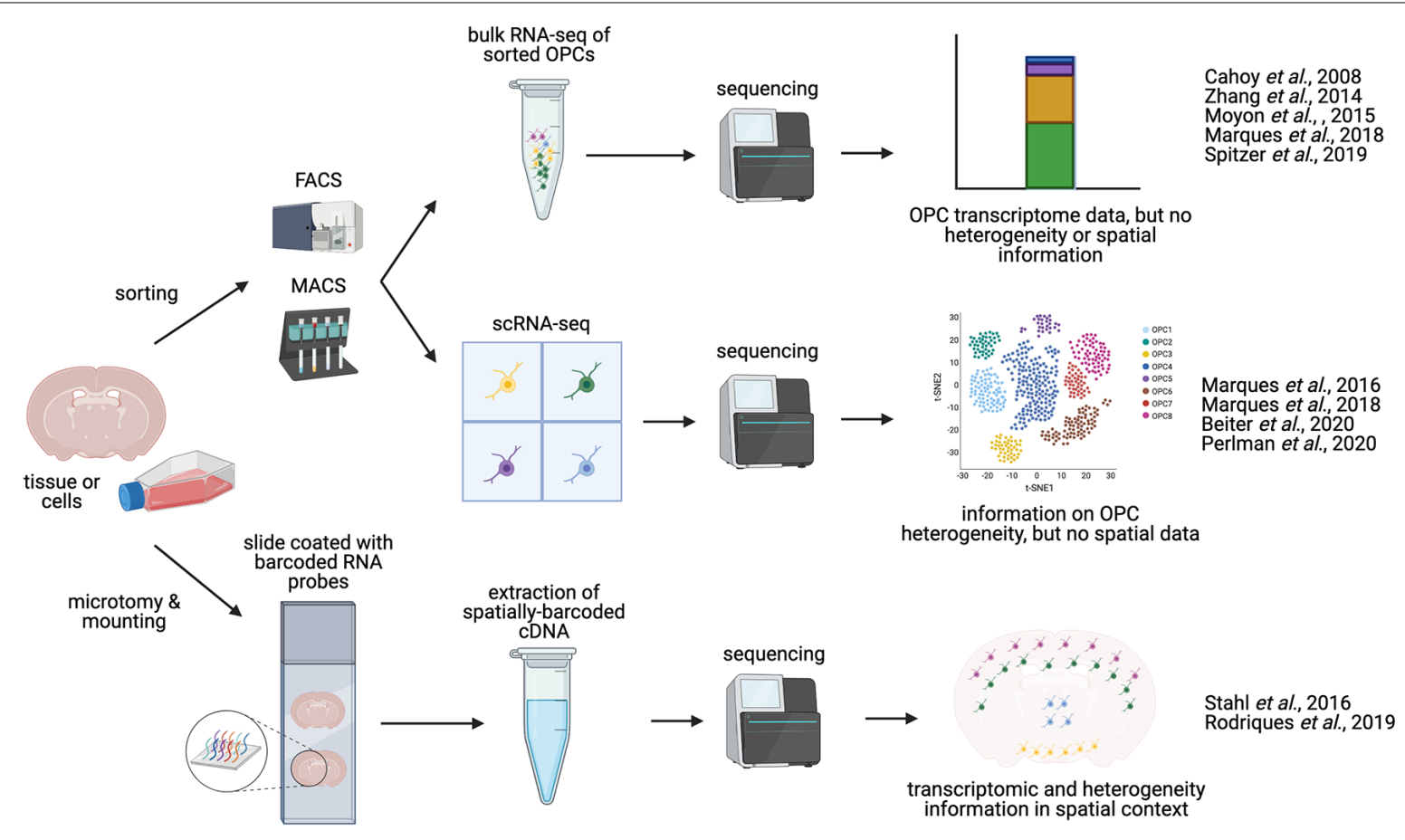

FIGURE 2 | Methodologies for charaterizing OPC transcriptomics and heterogeneity. OPCs can be isolated from whole brain or spinal cord tissue. Manual dissection of different regions of the brain or spinal cord allows for anatomical comparisons. OPCs can be enriched and isolated from tissues via FACS (Fluorescence-activated cell sorting) or magnetic activated cell sorted (MACS, magnetic-activated cell sorting), based on expression of OPC-specific cell-surface markers, such as NG2 or PDGFR $\alpha$. These sorted OPCs can then be processed and sequenced in bulk (bulk RNA-seq), or can be sequenced as single cells (scRNA-seq), yielding information on OPC heterogeneity and diversity. Alternatively, sequencing may be performed in situ on tissue sections [sc spatial RNA-seq or in situ sequencing (ISS)], producing single-cell transcriptomic data in a spatial context, and potentially mapping OPC heterogeneity to distinct anatomical regions.

Efforts towards understanding OPC morphology and the precise contacts they make with their neighboring cells promises to shed light on their potential functions. Conventional histological techniques, such as immunohistochemistry have highlighted important morphological differences between gray and white matter OPCs such as, as mentioned above, the former having radially orientated processes while in the latter, the processes are aligned parallel with neuronal axons (Levine et al., 2001). Of course, histological sectioning results in the loss of important volumetric information, which can otherwise more accurately inform on important parameters such as cell size, polarity, branch number, branch length, and the number of synapses and interacting cells (Hillman, 2000). Additionally, the categorization and measurement of relevant OPC parameters could be further enhanced by the use of computational techniques, such as "deep learning" which, in the case of studies concerning astrocytes, have already been used to characterize morphological parameters in a relatively unbiased manner (Kayasandik et al., 2020). It follows that investigations regarding OPC morphology may benefit from such computational techniques (Kayasandik et al., 2020), possibly highlighting previously unseen characteristics of OPCs which may provide functional insights.

Confocal microscopy has of course been essential in demonstrating the entire morphology of OPCs and oligodendrocytes (Eftekkharpour et al., 2007; Robins et al., 2013), while recent advances have facilitated imaging of whole cells in their in vivo context, such as light sheet fluorescence microscopy (Adams et al., 2015), two-photon or multiphoton microscopy (Table 1; Christensen and Nedergaard, 2011; Eugenin von Bernhardi and Dimou, 2019), and expansion microscopy (Wassie et al., 2019), with optical clearing allowing visualization of ever larger samples (Yu et al., 2018; Zhu et al., 2019). Zebrafish and Xenopus are especially useful for live imaging studies of OPCs and their lineage by light sheet fluorescence microscopy (LSFM; Bin and Lyons, 2016) or spinning disk confocal microscopy (Wang et al., 2018) due to the transparency of their embryos (Table 1). However with advances in optical clearing ( $Y u$ et al., 2018), brain tissues for larger animals (such as mice and rats) could be analyzed by two-photon or light sheet microscopy. OPC and OLs visualization could also be performed ex vivo (brain slice culture; Zhou et al., 2007; Gadea et al., 2009). At least with trans-cranial two-photon microscopy, in vivo visualization of OPCs and their lineage descendants can also be performed (Eugenin von Bernhardi and Dimou, 2019).

Furthermore, volumetric electron microscopy (such as ion beam-scanning electron microscopy; FIB-SEM) promise to more extensively reveal OPC/oligodendrocyte ultrastructure as already documented in the mouse optic nerve (Schertel et al., 2013) 
TABLE 1 | Imaging techniques.

\begin{tabular}{lll}
\hline Technique & Type of imaging & Applications \\
\hline (SBF-SEM) Serial & Destructive & Studying \\
block & scanning electron & sub-cellular \\
face-scanning & microscopy (serial & structures and \\
electron & ultramicrotome & cell-cell interactions \\
microscopy & sectioning) & in 3D
\end{tabular}

Major benefits
High resolution
(5-10 nm) through
$3 \mathrm{D}$ volume

(FIB-SEM)

beam-scanning

microscopy

Destructive

Studying

sub-cellular

structures and

ing electron

microscopy

cell-cell interactions

ablation of block in 3D ablation method

Better Z-resolution

than SBF-SEM

$(<10 \mathrm{~nm})$ due to

different surface

face)

Destroys the

sample, typically smaller total

volumes can be imaged than for SBF-SEM

Correlated light and electron microscopy on the same samples

Volumetric

fluroescent

microscopy (sheet of illuminating light)
EM-resolution of samples (cells and sub-cellular structures) with wider contextual information

Whole organism/organ imaging and tissue architecture
Places nm-scale EM resolution within the wider context of cells and tissues, allows for easier localization of nano-scale structures by first identifying them through fluorescent microscopy Non-destructive fluorescent imaging of whole animals, organs or tissues types of imaging

and careful

alignment of

data sets of the

same sample

Relatively low
Expansion microscopy
Fluorescent imaging of artificially expanded samples to increase resolution
Imaging organelles, synapses, synaptic vesicles and cell-cell interactions
High resolution beyond capabilities of typical light microscopy objectives, due to expansion of sample (effectively tens of $\mathrm{nm}$ )

Drawbacks
Destroys the
sample, feasible
only for a relatively
small total volume
(slow acquisition
and large data sets)

Notable uses
Characterization of
axon diameter and
myelination status
in transected
mouse optic nerve
$[5 \mathrm{~nm}(X-Y), 50 \mathrm{~nm}$

$(Z)$, total

volume $=50 \mu \mathrm{m}$

(X-Y), $100 \mu \mathrm{m}(Z)]$;

3D-reconstruction

of normal and

cuprizone-

demyelinated axons

in mouse corpus

callosum [1 nm

$(X-Y), 80 \mathrm{~nm}(Z)$,

area per

"slice" = 204.54

$\mu \mathrm{m} \times 61.36 \mu \mathrm{m}]$

$3 \mathrm{D}$ reconstruction

of organelles in a

myelinating

oligodendrocyte

within mouse optic

nerve $[7.5 \mathrm{~nm}$

resolution $(X-Y)$,

$30 \mathrm{~nm}(Z)$, total

volume $=7.72 \mu \mathrm{m}$

$(X), 5.79 \mu \mathrm{m}(\mathrm{Y})$

$3.81 \mu \mathrm{m}(Z)]$.

Requires multiple

separate imaging

Combined in vivo

multiphoton

microscopy,

confocal

microscopy, and

FIB-SEM on the

same samples of

mouse brain (using

myelinated axons

as landmarks) resolution (microns)

\begin{tabular}{|c|c|c|}
\hline $\begin{array}{l}\text { Relatively low } \\
\text { resolution (microns) }\end{array}$ & $\begin{array}{l}\text { Mapping expansion } \\
\text { and migration of } \\
\text { grafted human } \\
\text { neural progenitor } \\
\text { cells in mouse } \\
\text { (whole mouse } \\
\text { brain); identification } \\
\text { of functionally, } \\
\text { morphologically } \\
\text { and spatially } \\
\text { distinct subtypes of } \\
\text { OPC in zebrafish } \\
\text { spinal cord (entire } \\
\text { zebrafish larvae) }\end{array}$ & $\begin{array}{l}\text { Vogel et al. (2019) } \\
\text { and Marisca et al. } \\
\text { (2020) }\end{array}$ \\
\hline $\begin{array}{l}\text { Lengthy expansion } \\
\text { procedure; possible } \\
\text { distortion of tissue } \\
\text { architecture }\end{array}$ & $\begin{array}{l}\text { Super-resolution } \\
\text { visualization of } \\
\text { myelinated axons in } \\
\text { mouse } \\
\text { hippocampus } \\
(150-\mu m \text { thick } \\
\text { slices of mouse } \\
\text { brain) }\end{array}$ & Min et al. (2020) \\
\hline
\end{tabular}

Lengthy expansion procedure; possible distortion of tissue architecture

(Continued)

Reference(s)

Giacci et al. (2018)

and Fischbach

et al. (2019)

Schertel et al. (2013)

Luckner et al. (2018) 
TABLE 1 | Continued

\begin{tabular}{|c|c|c|c|c|c|c|}
\hline Technique & Type of imaging & Applications & Major benefits & Drawbacks & Notable uses & Reference(s) \\
\hline $\begin{array}{l}\text { Super-resolution } \\
\text { microscopy (e.g., } \\
\text { STED-Stimulated } \\
\text { Emission Depletion } \\
\text { Microscopy) }\end{array}$ & $\begin{array}{l}\text { Super-resolution } \\
\text { microscopy }\end{array}$ & $\begin{array}{l}\text { Imaging organelles, } \\
\text { synapses, synaptic } \\
\text { vesicles and } \\
\text { cell-cell interactions }\end{array}$ & $\begin{array}{l}\text { High resolution light } \\
\text { microscopy, } \\
\text { achieved by limiting } \\
\text { or negating the } \\
\text { inherent diffraction } \\
\text { of light }\end{array}$ & $\begin{array}{l}\text { Limited volumetric } \\
\text { information, most } \\
\text { super-resolution } \\
\text { techniques require } \\
\text { post-processing of } \\
\text { images (although } \\
\text { not STED) }\end{array}$ & $\begin{array}{l}\text { Demonstration of } \\
\text { preferential } \\
\text { interaction of OPCs } \\
\text { with the nodes of } \\
\text { Ranvier of large } \\
\text { diameter axons in } \\
\text { mouse CNS }\end{array}$ & $\begin{array}{l}\text { Serwanski et al. } \\
(2017)\end{array}$ \\
\hline $\begin{array}{l}\text { Synchrotron X-ray } \\
\text { microtomography }\end{array}$ & $\begin{array}{l}\text { Non-destructive } \\
\text { volumetric imaging }\end{array}$ & $\begin{array}{l}\text { 3D imaging organs } \\
\text { and tissues }\end{array}$ & $\begin{array}{l}\text { Better resolution } \\
\text { and contrast } \\
\text { compared to } \\
\text { conventional } \mu \mathrm{CT}\end{array}$ & $\begin{array}{l}\text { High energy X-rays } \\
\text { means cannot } \\
\text { image live } \\
\text { specimens, feasible } \\
\text { only for smaller total } \\
\text { volumes of } \\
\text { dissected tissue } \\
\text { (mm-scale) }\end{array}$ & $\begin{array}{l}\text { Visualization of } \\
\text { myelinated axons } \\
\text { and other } \\
\text { structures in a } \\
\text { subvolume of } \\
\text { mouse neocortex } \\
\text { (voxel size of } \\
\text { approx. } 1 \mu \mathrm{m}^{3} \text {, } \\
\text { mm-sized piece of } \\
\text { tissue) }\end{array}$ & Dyer et al. (2017) \\
\hline Multiphoton & $\begin{array}{l}\text { Non-invasive, } \\
\text { in vivo fluorescent } \\
\text { imaging }\end{array}$ & $\begin{array}{l}\text { Longitudinal or } \\
\text { time-lapse studies } \\
\text { in live animals or } \\
\text { cultured } \\
\text { organs/tissues }\end{array}$ & $\begin{array}{l}\text { Live imaging and } \\
\text { ability to image cells } \\
\text { and structures at } \\
\text { depth within } \\
\text { tissues, limited } \\
\text { photobleaching, } \\
\text { can perform optical } \\
\text { sectioning }\end{array}$ & $\begin{array}{l}\text { Relatively slow } \\
\text { acquisition, } \\
\text { resolution is not } \\
\text { superior to } \\
\text { conventional } \\
\text { confocal } \\
\text { microscopy }\end{array}$ & $\begin{array}{l}\text { Imaging of OPC } \\
\text { migration from SVZ } \\
\text { to cortex in } \\
\text { postnatal mouse } \\
\text { brain slices }\end{array}$ & Gadea et al. (2009) \\
\hline
\end{tabular}

and in the lamprey nervous system (Weil et al., 2018). Such destructive electron microscopy techniques use scanning electron microscopy (SEM) to image the surface of a specimen sample, combined with an ablation method that serially eliminates the surface layer resulting in a three-dimensional stack with $\mathrm{nm}$-scale resolution. Major techniques of this variety include FIB-SEM where a particle beam is used to ablate the sample surface (Schertel et al., 2013), and SBF-SEM (serial block face-SEM), where the sample is sectioned via microtome between images (Giacci et al., 2018; Fischbach et al., 2019; Table 1). These techniques are especially valuable when the research question requires careful identification of discrete organelles or other cellular structures that exist in a complicated 3D space. For example, FIB-SEM has been recently used to reconstruct the shape of abnormal unfolded myelin structures in mice lacking the Anilin gene in oligodendrocytes (Erwig et al., 2019). Physical interactions between OPCs and neurons could also be more effectively identified, classified and mapped in $3 \mathrm{D}$ by volumetric EM techniques, as has already been done for astrocyte-OPC interactions (Schertel et al., 2013) and more recently for synapses between astrocytes and neurons (Kikuchi et al., 2020).

Finally, imaging techniques that are based on the spin density of protons in water, notably magnetic resonance imaging (MRI) can also be used, given that the physical properties of myelin allow for it to be well contrasted against other brain tissues by virtue of its water content ( $40 \%$ compared to $80 \%$ respectively) (Alonso-Ortiz et al., 2015; Watanabe et al., 2016), and of course, MRI has the bonus of being non-invasive. However, the resolution given by MRI is not sufficient to allow for visualization of cells. CRISPR/Cas9 can also be used to facilitate a variety of imaging applications (reviewed by Galichet and LovellBadge, 2021). CRISPR/Cas9-mediated gene editing techniques that result in the epitope tagging of proteins have been developed to target neurons, and could be adapted to analyze OPCs in greater depth (Willems et al., 2020). In the next section, we discuss how the merging of functional and imaging approaches, in which light is used to modify gene expression, can be used to refine our understanding of OPC functions.

\section{FUNCTIONAL PHYSIOLOGICAL APPROACHES}

\section{Electrophysiology}

A recent study has used whole-cell patch clamp recordings in brain slice cultures to investigate the electrophysiological properties of NG2 positive OPCs through development and adulthood. It was observed that OPCs acquire electrophysiological heterogeneity with age, and that differences in excitability and ion channel expression are associated with distinct functional OPC states, including naïve, proliferative, primed and quiescent (Spitzer et al., 2019). While electrophysiological recordings are informative regarding ion channel expression, synapse formation and interaction with neurons and other cells, they can also provide helpful inferences regarding OPC morphology. Capacitance, a measure of stored charge, is dependent on cellular surface area, and can therefore be measured to indicate OPC size and morphology. Using this method, it was demonstrated that OPC capacitance is greatest during the active myelination phase of murine brain development (Spitzer et al., 2019). We have discussed above data showing that functional 
genetic approaches have revealed that OPC behavior and crosstalk with neighboring cells is region-specific. Therefore, future experiments that manage to achieve region-specific alterations, such as ablation of OPCs or their neighboring cells, would help understand the functional implications of this spatial heterogeneity.

\section{Functional Imaging and Optogenetics}

Novel techniques of improving our understanding of OPC functions include optogenetic, intra cellular ion signaling activity and imaging (Friess et al., 2016; Ortolani et al., 2018; Zhang M. et al., 2019; Heredia et al., 2020; Marisca et al., 2020). Optogenetics involves the use of light to modulate cells expressing a light-sensitive ion channel, and has historically been used primarily to modulate neuronal activity (Lee et al., 2020). Typically, a photo-sensitive variant of channel-rhodopsin 2 (ChR2) is used. Activation of ChR2 leads to the depolarization of the cell membrane which, in neurons, could trigger an action potential (Ernst et al., 2008). To study the importance of the transient early postnatal synaptic input from GABAergic interneurons to OPCs (Vélez-Fort et al., 2010), optogenetic methods have been used (Ortolani et al., 2018). Using Nkx2.1Cre and Parvalbumin ${ }^{\mathrm{Cre}}$, ChR2 was expressed in a subpopulation of interneurons. Upon light activation on 10-days old pups, cortical OPC proliferation and density was analyzed. However, neither were affected by the increased interneuron activity, thus supporting previous findings indicating that postnatal GABAergic activity does not affect cortical oligodendroglia (Balia et al., 2017; Ortolani et al., 2018). Optogenetics also allows the control of gene expression via light exposure (Yamada et al., 2020) and modulation of gene expression in OPCs in vivo by shining light in a region-specific manner is an approach that could be used in the future.

Calcium signaling is often involved in intracellular communication (but also in some other processes), however, this may subsequently lead to release of molecules that can affect adjacent cells. Upon entry into the cytosol, calcium ions often exert an allosteric effects on a plethora of enzymes and proteins to regulate their activity and function (Clapham, 2007). In terms of the properties or behavior of a cell, the effects of $\mathrm{Ca}^{2+}$ can be relatively rapid (e.g., release of a signaling molecule) or more long-term and global, e.g., via calmodulin or calcineurin to trigger nuclear entry of a transcription factor or phosphatase activity. As $\mathrm{Ca}^{2+}$ ions chelate with many chemicals, methods have been developed to measure calcium variation intra-cellularly. Typically, a fluorescent molecule is fused to a chelating agent to which $\mathrm{Ca}^{2+}$ can bind. Upon calcium binding, the quantum-yield of fluorescence is increased resulting in higher intensity signals where $\mathrm{Ca}^{2+}$ concentrations are elevated (Tsien, 1980; Grynkiewicz et al., 1985; Tsien, 1989; Dean et al., 2012). Calcium imaging and calcium signaling have been used in many contexts including the study of Schwann cells (Heredia et al., 2020) and oligodendrocytes (Zhang M. et al., 2019; Rui et al., 2020). Furthermore, using calcium imaging together with lineage tracing, single-cell transcriptomics and neuronal activity manipulation, Marisca et al. (2020) have dissected the functionality of different OPC subgroups in zebrafish spinal cord, where, as described earlier, the OPC population is heterogenous, both in spatial arrangement and in functionality (Marques et al., 2016, 2018; Foerster et al., 2019; Spitzer et al., 2019). In the zebrafish spinal cord, OPC subgroups have different degrees of calcium signaling activity, visualized using the calcium indicator GcaMP6m. Calcium imaging has revealed that, in embryonic zebrafish spinal cord, OPCs showing a higher rate of calcium signaling activity are less likely to differentiate directly (Marisca et al., 2020). Furthermore, in vitro and ex vivo studies have demonstrated that intracellular calcium, alongside intracellular sodium and potassium, influence myelin basic protein synthesis in OPCs (Friess et al., 2016).

\section{CULTURE SYSTEMS}

Several approaches can be taken to grow and manipulate OPCs in vitro, where the primary advantages are more precisely defined conditions and greater experimental tractability. Methods such as these also allow for rapid and efficient generation of OPCs and OLs, which can then be used for therapeutic purposes as part of regenerative medicine (Egawa et al., 2016; Morales Pantoja et al., 2020), or used for further experiments, such as in drug screens to identify treatments for demyelinating diseases, glioma or CNS injuries (Badr et al., 2011; Lariosa-Willingham et al., 2016). In particular, the generation of patient-derived OPCs and OLs via human induced pluripotent stem cells (hiPSCs) allows for the study of cell and molecular processes underlying human disease (for review: Chanoumidou et al., 2020). Furthermore, adoption of three-dimensional culture systems has enabled the study of OPCs in contexts that better recapitulate the in vivo environment (Chiaradia and Lancaster, 2020).

OPCs can be obtained and differentiated from mouse epiblast stem cells (Najm et al., 2011; Lager et al., 2018), from human embryonic stem cells (hESCs) or hiPSCs (Wang et al., 2013; Kim et al., 2017; Biswas et al., 2019) or by trans-differentiation of other cell types (e.g., fibroblasts) by CRISPR/Cas9-mediated gene activation (Matjusaitis et al., 2019). OPCs can also be derived from different post-natal brain regions in mice (Yang et al., 2016) by manually dissecting the region of interest and using the "shake-off" technique to discard dead or terminally differentiated cells and cells that have different adhesion properties, namely astrocytes and microglia, thereby leaving only proliferative, adherent progenitor cells (Chen et al., 2007; O’Meara et al., 2011; Medina-Rodríguez et al., 2013). Spheres of oligodendrocyte lineage cells, also known as "oligospheres" can also be obtained from multipotent mouse or rat cortical progenitor cells (Chen et al., 2007; Pedraza et al., 2008). The composition of such cultures usually requires validation by immunocytochemistry to determine the proportions of different cell types (Vitry et al., 1999; Chen et al., 2007). In comparison, purified OPC cultures can also be derived by dissociating cells from tissues and sorting for OPC-specific markers by FACS or MACS (Barateiro and Fernandes, 2014). Furthermore, zebrafishderived OPC cultures may be ideally suited for studying fundamental processes and for small molecule screens, and can also be co-cultured with human cells (Kroehne et al., 2017). 
Differentiation of OPCs and subsequently OLs from hiPSCs or hESCs can be achieved by recapitulating the signaling processes associated with differentiation (Goldman and Kuypers, 2015), either pharmacologically by timely addition of agonist and antagonists during the differentiation process (Douvaras and Fossati, 2015), or by driving expression of key regulatory genes, such as SOX10 and OLIG2 in ESCs (Pawlowski et al., 2017), or SOX10, OLIG2 and NKX6.2 (Ehrlich et al., 2017) and SOX9 in hiPSCs (Ng et al., 2020). A combination of both pharmacological and genetic differentiation methodologies can also be used to great synergistic effect (García-León et al., 2020). As mentioned, these protocols enable the production of relatively large amounts of OPCs and OLs, which can be used therapeutically (Egawa et al., 2016; Morales Pantoja et al., 2020) or for experimentation. Xenograft experiments have shown that hiPSC-derived OPCs/OLs survive and can influence disease processes in model animals (Wang et al., 2013b; Kawabata et al., 2016; Feng et al., 2020; Ng et al., 2020). Finally, and perhaps most illuminating are studies where patient-derived iPSCs are used to make OPCs/OLs, which are then used to study disease processes (for review: Chanoumidou et al., 2020).

For example, Palizaeus-Merzbacher disease (PMD) is a rare pediatric monogenic condition affecting myelin in the CNS, which is linked to a variety of mutations in proteolipid protein 1 (PLP1). Using hiPSCs derived from different patients, a screen was developed that linked particular mutations in PLP1 with specific phenotypes, such as regarding ability to develop OPCs and form OLs, cellular morphology, and myelination capacity (Nevin et al., 2017). More recently, OLs derived from MS patient iPSCs have shed light on the importance of the extracellular milieu, indicating that OPCs in the context of MS are more sensitive to inflammatory environments, which impairs their ability to differentiate (Morales Pantoja et al., 2020). The use of hiPSC or hESC-derived OPCs/OLs, in combination with "omic" methodologies described above, provide a deeper understanding of differences in gene expression between OPCs in health and disease (Lopez-Caraballo et al., 2020; Ng et al., 2020; Chamling et al., 2021). Bulk RNA-seq of hiPSC-derived OPCs for example, has indicated transcriptomic differences between OPCs in healthy donors and MS patients. Further proteomic characterization of OPC-condition media revealed that MS-associated OPCs are likely less able to promote migration of other OPCs, which was subsequently confirmed via in vitro migration assays (Lopez-Caraballo et al., 2020).

The utility of iPSC cultures for understanding OPCs in disease is, of course, not limited to the generation of OL-lineage cells. For example, it has been shown that neural progenitor cells, differentiated from hiPSCs of MS patients, were unable to promote maturation of OPCs compared to healthy neural progenitor cells, and this was linked to expression of cellular senescence genes in MS-derived neural progenitors (Nicaise et al., 2019). Another study has shown that astrocytes derived from patient iPSCs suffering from Alexander disease, which is a rare genetic leukodystrophy that features demyelination, inhibit proliferation and differentiation of OPCs in co-culture (Li et al., 2018).
Furthermore, the culture of iPSC-derived OPCs as well as from other sources, has been advanced by the incorporation of 3D culture systems. Such methods not only increase the efficiency of generation of OPCs and OLs, but also better recapitulate the in vivo environment, allowing for more accurate and translational studies of their biology (Rodrigues et al., 2017). Here, we will refer to both spheroids and organoids, where spheroids are small "balls" of cells of usually one or two cell types (Birey et al., 2017), and organoids being larger accumulations of cells comprised of heterogenous cell types which more closely resemble actual tissues (Chiaradia and Lancaster, 2020). For example, 3D cultures have been made by aggregation of hiPSCs, which through timely addition of signaling pathway modifiers, generate oligodendrocyte spheroids. These 3D spheroids contain cells of the OPC lineage and myelinated neurons and thus can be used for OL development and interaction with other cells (Marton et al., 2019). One limitation of cerebral organoids has been that the emergence of myelinating OLs within cerebral organoids can take a long time; between 103 and 210 days (Madhavan et al., 2018; Marton et al., 2019). However, in a recent study, hiPSCs were simultaneously differentiated into organoids containing both neurons and OL-lineage cells through a combination of differentiation media and induction of expression of cell autonomously-acting transcription factors (Ng et al., 2020). This method resulted in rapid formation of myelinating-oligodendrocytes and production of myelinated neuronal axons at a density comparable to that of healthy human brains (Ng et al., 2020). Such neuronal/OL co-cultures also allow for direct study of the process of axonal myelination in both healthy and diseased contexts using patient-derived cells (Pang et al., 2018; Assetta et al., 2020). 3D culture systems are of course also useful in glial tumor research, where gliomas and glioblastomas cultured as either tumor-spheres or as organoids permit maintenance of 3D tumor architecture (Ogawa et al., 2018; Azzarelli, 2020) and tumor heterogeneity (Jacob et al., 2020) compared to 2D culture systems (Melissaridou et al., 2019; Ruiz-Garcia et al., 2020). Brain slice cultures are also of importance in this context. For example, time-lapse imaging of brain slices could shed light on the invasiveness and evolution of gliomas as well as the cell of origin (Fayzullin et al., 2016).

Finally, the utility of conventional 2D culture systems should not be discounted, as they are nonetheless invaluable and eminently tractable methods of examining more specific aspects of OPC biology. Indeed, many of the iPSC studies described above were conducted in monolayer cultures (Wang et al., 2013; Kim et al., 2017; Yamashita et al., 2017; Biswas et al., 2019; Assetta et al., 2020). To give some further examples, treatment of in vitro cultured OPCs with various endocannabinoid ligands and antagonists has highlighted the potential regulatory role of the endocannabinoid system in regulating OPCs in both health and disease (for review: Ilyasov et al., 2018). Incubation of immortalized rat cerebral endothelial cells with media conditioned with primary rat OPCs resulted in increased expression of tight junction proteins and decreased transwell permeability, indicating a role of OPCs in maintaining the BBB (Seo et al., 2014). Lastly, culture of hiPSC-derived OPCs on substrates of varying stiffness has demonstrated that 
OPC migration is both mechanosensitive and donor-dependent (Espinosa-Hoyos et al., 2020).

\section{CONCLUSIONS}

Oligodendrocytes, arising from oligodendrocyte progenitor cells (OPCs) or NG2-glia, are crucial cells in the nervous system facilitating rapid electrical conductance in neurons. While originally OPCs were thought of only as the precursors of oligodendrocytes, they are also able to generate other cell types including neurons and astrocytes (Figure 1), and that they have functions of their own (Rivers et al., 2008; Zhu et al., 2008a,b; Guo et al., 2010). OPCs are fully integrated in the CNS, receiving inputs from and affecting the behavior of neighboring cells including neurons, astrocytes and microglia (Domingues et al., 2016; Nutma et al., 2020). It is important to note that the appearance of OPCs from ESCs in humans follow some similar conserved transcriptional networks but also respond differently to certain factors, such as FGF2 (Hu et al., 2009; Bribián et al., 2019). It is therefore essential to understand these differences before comparing OPCs and other OL-lineage cells between species.

While OPCs share core markers, it has become increasingly clear that adult OPCs are heterogenous in their transcriptomes (Marques et al., 2016, 2018; Beiter et al., 2020). However, it is not currently fully understood how this transcriptomic heterogeneity translates into functional heterogeneity. Furthermore, OPC location may also reflect differences in OPC functions, such as illustrated with perivascular OPCs promoting angiogenesis as described under cerebral ischemia conditions (Kishida et al., 2019). With advances in transcriptomic analysis and discovery of markers specific to sub-populations of OPCs, these cells could now be sorted according to their location and/or transcriptomic profile and ATAC-seq, bisulfite-seq or proteomic studies could be performed at a single-cell level (Kashima et al., 2020). Such methods could also be applied to analyze OPCs in disease conditions.

Advances in imaging and functional imaging have allowed a better understanding of OPC localization, differentiation and relationship with other cell types. While the neuronal connectome is fundamental to understanding information processing (Oh et al., 2014), one could think of determining the OPC-specific connectome to refine our understanding of OPC integration within the CNS. With functional imaging techniques, OPCs could be ablated or have their gene expression altered in a position specific manner; this would permit further understanding of the link between OPC location and function.

\section{REFERENCES}

Adams, M. W., Loftus, A. F., Dunn, S. E., Joens, M. S., and Fitzpatrick, J. A. J. (2015). Light sheet fluorescence microscopy (LSFM). Curr. Protoc. Cytom. 71, 12.37.1-12.37.15. doi: 10.1002/0471142956.cy1237s71

Ahlgren, S. C., Wallace, H., Bishop, J., Neophytou, C., and Raff, M. C. (1997). Effects of thyroid hormone on embryonic oligodendrocyte precursor cell development in vivo and in vitro. Mol. Cell. Neurosci. 9, 420-432. doi: $10.1006 /$ mcne.1997.0631
Conditions affecting the function of myelin, as well as gliomas, have profound health consequences in which OPCs most likely have an etiological role to play and could be target cells for drug discovery experiments. Indeed, in specific cases of gliomas, OPCs seem to be the cell of origin (Zong et al., 2015). A greater understanding of the heterogeneity of OPCs would permit studies to determine whether gliomas that arise from NG2-glia involve a specific sub-type(s). Such information would permit a more targeted approach to treatments. In diseases affecting myelin function, such as MS or Devic's disease (Duncan and Radcliff, 2016), it is crucial to direct OPCs to promote regeneration and remyelination. It is also important to investigate whether, for these conditions, OPCs are not themselves contributing to disease processes. For example, multiple sclerosis is an auto-immune disease affecting myelin, and OPCs contribute to brain immunity (Domingues et al., 2016) and may act as immune responder cells (Seo et al., 2013); hence a better understanding of the potential different OPC functions may help to tackle disease response and evolution. Furthermore, as OPCs are the most proliferative cells within the CNS, one could think of directing their fate in response to specific injuries (for example, generation of neurons after stroke).

It is therefore crucial to fully understand populations of OPCs; their diversity and the different functions they may have. Increased knowledge would permit the use and/or the manipulation of these cells in different neurological contexts, including those involving aging, inflammation, cancer, or degeneration.

\section{AUTHOR CONTRIBUTIONS}

CG and RC wrote the initial review. CG, RC and RL-B contributed to the critical reading of the review. All authors contributed to the article and approved the submitted version.

\section{FUNDING}

This review article was supported by the Francis Crick Institute which receives its core funding from Cancer Research UK (FC001107), the UK Medical Research Council (FC001107) and the Wellcome Trust (FC001107). This work was also supported by an additional UK Medical Research Council grant (reference MR/T000759/1).

\section{ACKNOWLEDGMENTS}

All figures were created with BioRender.com.

Alonso-Ortiz, E., Levesque, I. R., and Pike, G. B. (2015). MRI-based myelin water imaging: a technical review. Magn. Reson. Med. 73, 70-81. doi: 10.1002/mrm. 25198

Andrae, J., Gouveia, L., Gallini, R., He, L., Fredriksson, L., Nilsson, I., et al. (2016). A role for PDGF-C/PDGFR $\alpha$ signaling in the formation of the meningeal basement membranes surrounding the cerebral cortex. Biol. Open 5, 461-474. doi: 10.1242/bio.017368

Assetta, B., Tang, C., Bian, J., O’rourke, R., Connolly, K., Brickler, T., et al. (2020). Generation of human neurons and oligodendrocytes from pluripotent 
stem cells for modeling neuron-oligodendrocyte interactions. J. Vis. Exp. 9:165. doi: $10.3791 / 61778$

Azzarelli, R. (2020). Organoid models of glioblastoma to study brain tumor stem cells. Front. Cell Dev. Biol. 8:220. doi: 10.3389/fcell.2020.00220

Badr, C. E., Wurdinger, T., and Tannous, B. A. (2011). Functional drug screening assay reveals potential glioma therapeutics. Assay Drug Dev. Technol. 9, 281-289. doi: 10.1089/adt.2010.0324

Balia, M., Benamer, N., and Angulo, M. C. (2017). A specific GABAergic synapse onto oligodendrocyte precursors does not regulate cortical oligodendrogenesis. Glia 65, 1821-1832. doi: 10.1002/glia.23197

Barateiro, A., and Fernandes, A. (2014). Temporal oligodendrocyte lineage progression: in vitro models of proliferation, differentiation and myelination. Biochim. Biophys. Acta 1843, 1917-1929. doi: 10.1016/j.bbamcr.2014.04.018

Baydyuk, M., Morrison, V. E., Gross, P. S., and Huang, J. K. (2020). Extrinsic factors driving oligodendrocyte lineage cell progression in CNS development and injury. Neurochem. Res. 45, 630-642. doi: 10.1007/s11064-020-02967-7

Beiter, R. M., Fernández-Castañeda, A., Rivet-Noor, C., Merchak, A., Bai, R., Slogar, E., et al. (2020). Evidence for oligodendrocyte progenitor cell heterogeneity in the adult mouse brain. bioRxiv [Preprint]. doi: 10.1101/2020. 03.06.981373

Bergles, D. E., and Richardson, W. D. (2015). Oligodendrocyte development and plasticity. Cold Spring Harb. Perspect. Biol. 8:a020453. doi: 10.1101/cshperspect. a020453

Bergles, D. E., Roberts, J. D., Somogyi, P., and Jahr, C. E. (2000). Glutamatergic synapses on oligodendrocyte precursor cells in the hippocampus. Nature 405, 187-191. doi: $10.1038 / 35012083$

Bin, J. M., and Lyons, D. A. (2016). Imaging myelination in vivo using transparent animal models. Brain Plast. 2, 3-29. doi: 10.3233/BPL-160029

Birey, F., Andersen, J., Makinson, C. D., Islam, S., Wei, W., Huber, N., et al. (2017). Assembly of functionally integrated human forebrain spheroids. Nature 545, 54-59. doi: 10.1038/nature22330

Birey, F., Kloc, M., Chavali, M., Hussein, I., Wilson, M., Christoffel, D. J., et al. (2015). Genetic and stress-induced loss of NG2 glia triggers emergence of depressive-like behaviors through reduced secretion of FGF2. Neuron 88, 941-956. doi: 10.1016/j.neuron.2015.10.046

Biswas, S., Chung, S. H., Jiang, P., Dehghan, S., and Deng, W. (2019). Development of glial restricted human neural stem cells for oligodendrocyte differentiation in vitro and in vivo. Sci. Rep. 9:9013. doi: 10.1038/s41598-019-45247-3

Borges, H. L., Linden, R., and Wang, J. Y. J. (2008). DNA damage-induced cell death: lessons from the central nervous system. Cell Res. 18, 17-26. doi: $10.1038 /$ cr.2007.110

Boshans, L. L., Sherafat, A., and Nishiyama, A. (2020). The effects of developmental and current niches on oligodendrocyte precursor dynamics and fate. Neurosci. Lett. 715:134593. doi: 10.1016/j.neulet.2019.134593

Bouabe, H., and Okkenhaug, K. (2013). Gene targeting in mice: a review. Methods Mol. Biol. 1064, 315-336. doi: 10.1007/978-1-62703-601-6_23

Bribián, A., Medina-Rodríguez, E., Josa-Prado, F., García-Álvarez, I., MachínDíaz, I., Murcia-Belmonte, V., et al. (2019). Age-linked heterogeneity among oligodendrocyte precursor cells in the cerebral cortex of mice and human. bioRxiv [Preprint]. doi: 10.1101/799544

Cahoy, J. D., Emery, B., Kaushal, A., Foo, L. C., Zamanian, J. L., Christopherson, K. S., et al. (2008). A transcriptome database for astrocytes, neurons and oligodendrocytes: a new resource for understanding brain development and function. J. Neurosci. 28, 264-278. doi: 10.1523/JNEUROSCI. 4178-07.2008

Chamling, X., Kallman, A., Fang, W., Berlinicke, C. A., Mertz, J. L., Devkota, P., et al. (2021). Single-cell transcriptomic reveals molecular diversity and developmental heterogeneity of human stem cell-derived oligodendrocyte lineage cells. Nat. Commun. 12:652. doi: 10.1038/s41467-021-20892-3

Chanoumidou, K., Mozafari, S., Baron-Van Evercooren, A., and Kuhlmann, T. (2020). Stem cell derived oligodendrocytes to study myelin diseases. Glia 68, 705-720. doi: $10.1002 /$ glia. 23733

Chari, D. M., and Blakemore, W. F. (2002). Efficient recolonisation of progenitordepleted areas of the CNS by adult oligodendrocyte progenitor cells. Glia 37, 307-313. doi: 10.1002/glia.10038

Cheli, V. T., Santiago Gonzalez, D. A., Namgyal Lama, T., Spreuer, V., Handley, V., Murphy, G. G., et al. (2016). Conditional deletion of the L-type calcium channel Cav1.2 in oligodendrocyte progenitor cells affects postnatal myelination in mice. J. Neurosci. 36, 10853-10869. doi: 10.1523/JNEUROSCI.1770 $-16.2016$

Cheli, V. T., Santiago González, D. A., Spreuer, V., and Paez, P. M. (2015). Voltagegated $\mathrm{Ca} 2+$ entry promotes oligodendrocyte progenitor cell maturation and myelination in vitro. Exp. Neurol. 265, 69-83. doi: 10.1016/j.expneurol.2014. 12.012

Chen, Y., Balasubramaniyan, V., Peng, J., Hurlock, E. C., Tallquist, M., Li, J., et al. (2007). Isolation and culture of rat and mouse oligodendrocyte precursor cells. Nat. Protoc. 2, 1044-1051. doi: 10.1038/nprot.2007.149

Chen, T. J., Kula, B., Nagy, B., Barzan, R., Gall, A., Ehrlich, I., et al. (2018). In vivo regulation of oligodendrocyte precursor cell proliferation and differentiation by the AMPA-receptor subunit GluA2. Cell Rep. 25, 852-861. doi: 10.1016/j. celrep.2018.09.066

Chen, R., Wu, X., Jiang, L., and Zhang, Y. (2017). Single-cell RNA-seq reveals hypothalamic cell diversity. Cell Rep. 18, 3227-3241. doi: 10.1016/j.celrep.2017. 03.004

Chiaradia, I., and Lancaster, M. A. (2020). Brain organoids for the study of human neurobiology at the interface of in vitro and in vivo. Nat. Neurosci. 23, 1496-1508. doi: 10.1038/s41593-020-00730-3

Christensen, D. J., and Nedergaard, M. (2011). Two-photon in vivo imaging of cells. Pediatr. Nephrol. 26, 1483-1489. doi: 10.1007/s00467-011-1818-9

Clapham, D. E. (2007). Calcium signaling. Cell 131, 1047-1058. doi: 10.1016/j.cell. 2007.11.028

Clarke, L. E., Young, K. M., Hamilton, N. B., Li, H., Richardson, W. D., and Attwell, D. (2012). Properties and fate of oligodendrocyte progenitor cells in the corpus callosum, motor cortex and piriform cortex of the mouse. J. Neurosci. 32, 8173-8185. doi: 10.1523/JNEUROSCI.0928 $-12.2012$

Dawson, M. R., Levine, J. M., and Reynolds, R. (2000). NG2-expressing cells in the central nervous system: are they oligodendroglial progenitors? J. Neurosci. Res. 61, 471-479. doi: 10.1002/1097-4547(20000901)61:5<471::AID-JNR1 > 3.0. $\mathrm{CO} ; 2-\mathrm{N}$

Dawson, M. R., Polito, A., Levine, J. M., and Reynolds, R. (2003). NG2-expressing glial progenitor cells: an abundant and widespread population of cycling cells in the adult rat CNS. Mol. Cell. Neurosci. 24, 476-488. doi: 10.1016/s10447431(03)00210-0

Dean, K. M., Qin, Y., and Palmer, A. E. (2012). Visualizing metal ions in cells: an overview of analytical techniques, approaches, and probes. Biochim. Biophys. Acta 1823, 1406-1415. doi: 10.1016/j.bbamcr.2012.04.001

Deshmane, S. L., Kremlev, S., Amini, S., and Sawaya, B. E. (2009). Monocyte chemoattractant protein-1 (MCP-1): an overview. J. Interferon Cytokine Res. 29, 313-326. doi: 10.1089/jir.2008.0027

Dimou, L., and Gallo, V. (2015). NG2-glia and their functions in the central nervous system. Glia 63, 1429-1451. doi: 10.1002/glia.22859

Djogo, T., Robins, S. C., Schneider, S., Kryzskaya, D., Liu, X., Mingay, A., et al. (2016). Adult NG2-glia are required for median eminence-mediated leptin sensing and body weight control. Cell Metab. 23, 797-810. doi: 10.1016/j.cmet. 2016.04.013

Domingues, H. S., Portugal, C. C., Socodato, R., and Relvas, J. B. (2016). Oligodendrocyte, astrocyte and microglia crosstalk in myelin development, damage and repair. Front. Cell Dev. Biol. 4:71. doi: 10.3389/fcell.2016. 00071

Douglas Fields, R. (2015). A new mechanism of nervous system plasticity: activitydependent myelination. Nat. Rev. Neurosci. 16, 756-767. doi: 10.1038/nrn4023

Douvaras, P., and Fossati, V. (2015). Generation and isolation of oligodendrocyte progenitor cells from human pluripotent stem cells. Nat. Protoc. 10, 1143-1154. doi: 10.1038/nprot.2015.075

Dumas, L., Heitz-Marchaland, C., Fouquet, S., Suter, U., Livet, J., MoreauFauvarque, C., et al. (2015). Multicolor analysis of oligodendrocyte morphology, interactions and development with Brainbow. Glia 63, 699-717. doi: 10.1002/glia.22779

Duncan, I. D., and Radcliff, A. B. (2016). Inherited and acquired disorders of myelin: the underlying myelin pathology. Exp. Neurol. 283, 452-475. doi: 10.1016/j.expneurol.2016.04.002

Dyer, E. L., Gray Roncal, W., Prasad, J. A., Fernandes, H. L., Gürsoy, D., De Andrade, V., et al. (2017). Quantifying mesoscale neuroanatomy using X-ray microtomography. eNeuro 4:ENEURO.0195-0117.2017. doi: 10.1523/ENEURO.0195-17.2017 
Eftekkharpour, E., Karimi-Abdolrezaee, S., Wang, J., El-Beheiry, H., Morshead, C., and Fehlings, M. (2007). Myelination of congenitally dysmyelinated spinal cord axons by adult neural precursor cells results in formation of nodes of ranvier and improved axonal conduction. J. Neurosci. 27, 3416-3428. doi: 10.1523/JNEUROSCI.0273-07.2007

Egawa, N., Takase, H., Josephine, L., Takahashi, R., and Arai, K. (2016). Clinical application of oligodendrocyte precursor cells for cell-based therapy. Brain Circ. 2, 121-125. doi: 10.4103/2394-8108.192515

Ehrlich, M., Mozafari, S., Glatza, M., Starost, L., Velychko, S., Hallmann, A. L., et al. (2017). Rapid and efficient generation of oligodendrocytes from human induced pluripotent stem cells using transcription factors. Proc. Natl. Acad. Sci. U S A 114, E2243-E2252. doi: 10.1073/pnas.1614412114

Elbaz, B., and Popko, B. (2019). Molecular control of oligodendrocyte development. Trends Neurosci. 42, 263-277. doi: 10.1016/j.tins.2019.01.002

Ernst, O. P., Sánchez Murcia, P. A., Daldrop, P., Tsunoda, S. P., Kateriya, S., and Hegemann, P. (2008). Photoactivation of channelrhodopsin. J. Biol. Chem. 283, 1637-1643. doi: 10.1074/jbc.M708039200

Erwig, M. S., Patzig, J., Steyer, A. M., Dibaj, P., Heilmann, M., Heilmann, I., et al. (2019). Anillin facilitates septin assembly to prevent pathological outfoldings of central nervous system myelin. eLife 8:e43888. doi: 10.7554/eLife. 43888

Espinosa-Hoyos, D., Burstein, S. R., Cha, J., Jain, T., Nijsure, M., Jagielska, A., et al. (2020). Mechanosensitivity of human oligodendrocytes. Front. Cell. Neurosci. 14:222. doi: $10.3389 /$ fncel.2020.00222

Eugenín-Von Bernhardi, J., and Dimou, L. (2016). NG2-glia, more than progenitor cells. Adv. Exp. Med. Biol. 949, 27-45. doi: 10.1007/978-3-319-4 0764-7_2

Eugenin von Bernhardi, J., and Dimou, L. (2019). Recent advances in live imaging of cells of the oligodendrocyte lineage. Methods Mol. Biol. 1936, 275-294. doi: 10.1007/978-1-4939-9072-6_16

Fayzullin, A., Tuvnes, F. A., Skjellegrind, H. K., Behnan, J., Mughal, A. A., Langmoen, I. A., et al. (2016). Time-lapse phenotyping of invasive glioma cells ex vivo reveals subtype-specific movement patterns guided by tumor core signaling. Exp. Cell Res. 349, 199-213. doi: 10.1016/j.yexcr.2016.08.001

Feng, L., Chao, J., Tian, E., Li, L., Ye, P., Zhang, M., et al. (2020). Cell-based therapy for canavan disease using human iPSC-derived NPCs and OPCs. Adv. Sci. 7:2002155. doi: 10.1002/advs.202002155

Fischbach, F., Nedelcu, J., Leopold, P., Zhan, J., Clarner, T., Nellessen, L., et al. (2019). Cuprizone-induced graded oligodendrocyte vulnerability is regulated by the transcription factor DNA damage-inducible transcript 3. Glia 67, 263-276. doi: 10.1002/glia.23538

Foerster, S., Hill, M. F. E., and Franklin, R. J. M. (2019). Diversity in the oligodendrocyte lineage: plasticity or heterogeneity? Glia 67, 1797-1805. doi: 10.1002/glia.23607

Friess, M., Hammann, J., Unichenko, P., Luhmann, H. J., White, R., and Kirischuk, S. (2016). Intracellular ion signaling influences myelin basic protein synthesis in oligodendrocyte precursor cells. Cell Calcium 60, 322-330. doi: 10.1016/j.ceca.2016.06.009

Gadea, A., Aguirre, A., Haydar, T. F., and Gallo, V. (2009). Endothelin1 regulates oligodendrocyte development. J. Neurosci. 29, 10047-10062. doi: 10.1523/JNEUROSCI.0822-09.2009

Galichet, C., and Lovell-Badge, R. (2021). Applications of genome editing on laboratory animals. Lab. Anim. doi: 10.1177/0023677221993141. [Epub ahead of print].

Galvao, R. P., Kasina, A., Mcneill, R. S., Harbin, J. E., Foreman, O., Verhaak, R. G. W., et al. (2014). Transformation of quiescent adult oligodendrocyte precursor cells into malignant glioma through a multistep reactivation process. Proc. Natl. Acad. Sci. U S A 111, E4214-E4223. doi: 10.1073/pnas.1414389111

García-León, J. A., García-Díaz, B., Eggermont, K., Cáceres-Palomo, L., Neyrinck, K., Madeiro Da Costa, R., et al. (2020). Generation of oligodendrocytes and establishment of an all-human myelinating platform from human pluripotent stem cells. Nat. Protoc. 15, 3716-3744. doi: 10.1038/s41596-020-0395-4

Giacci, M. K., Bartlett, C. A., Huynh, M., Kilburn, M. R., Dunlop, S. A., and Fitzgerald, M. (2018). Three dimensional electron microscopy reveals changing axonal and myelin morphology along normal and partially injured optic nerves. Sci. Rep. 8:3979. doi: 10.1038/s41598-018-22361-2
Goldman, S. A., and Kuypers, N. J. (2015). How to make an oligodendrocyte. Development 142, 3983-3995. doi: 10.1242/dev.126409

González-Orozco, J. C., Moral-Morales, A. D., and Camacho-Arroyo, I. (2020). Progesterone through progesterone receptor b isoform promotes rodent embryonic oligodendrogenesis. Cells 9:960. doi: 10.3390/cells9040960

Gregath, A., and Lu, Q. R. (2018). Epigenetic modifications-insight into oligodendrocyte lineage progression, regeneration, and disease. FEBS Lett. 592, 1063-1078. doi: 10.1002/1873-3468.12999

Grynkiewicz, G., Poenie, M., and Tsien, R. Y. (1985). A new generation of $\mathrm{Ca}^{2+}$ indicators with greatly improved fluorescence properties. J. Biol. Chem. 260, 3440-3450. doi: 10.1016/s0021-9258(19)83641-4

Guo, F., Maeda, Y., Ma, J., Xu, J., Horiuchi, M., Miers, L., et al. (2010). Pyramidal neurons are generated from oligodendroglial progenitor cells in adult piriform cortex. J. Neurosci. 30, 12036-12049. doi: 10.1523/JNEUROSCI.1360-10.2010

Haberlandt, C., Derouiche, A., Wyczynski, A., Haseleu, J., Pohle, J., Karram, K., et al. (2011). Gray matter NG2 cells display multiple $\mathrm{Ca}^{2+}$-signaling pathways and highly motile processes. PLoS One 6:e17575. doi: 10.1371/journal.pone. 0017575

Habib, N., Avraham-Davidi, I., Basu, A., Burks, T., Shekhar, K., Hofree, M., et al. (2017). Massively parallel single-nucleus RNA-seq with DroNc-seq. Nat. Methods 14, 955-958. doi: 10.1038/nmeth.4407

Habib, N., Li, Y., Heidenreich, M., Swiech, L., Avraham-Davidi, I., Trombetta, J. J., et al. (2016). Div-Seq: single-nucleus RNA-Seq reveals dynamics of rare adult newborn neurons. Science 353, 925-928. doi: 10.1126/science.aad7038

Heredia, D. J., De Angeli, C., Fedi, C., and Gould, T. W. (2020). Calcium signaling in schwann cells. Neurosci. Lett. 729:134959. doi: 10.1016/j.neulet.2020.134959

Hernández-Hernández, O., Ávila-Avilés, R. D., and Hernández-Hernández, J. M. (2020). Chromatin landscape during skeletal muscle differentiation. Front. Genet. 11:578712. doi: 10.3389/fgene.2020.578712

Hesp, Z. C., Yoseph, R. Y., Suzuki, R., Jukkola, P., Wilson, C., Nishiyama, A., et al. (2018). Proliferating NG2-cell-dependent angiogenesis and scar formation alter axon growth and functional recovery after spinal cord injury in mice. J. Neurosci. 38, 1366-1382. doi: 10.1523/JNEUROSCI.3953 $-16.2017$

Hill, R. A., Patel, K. D., Medved, J., Reiss, A. M., and Nishiyama, A. (2013). NG2 cells in white matter but not gray matter proliferate in response to PDGF. J. Neurosci. 33, 14558-14566. doi: 10.1523/JNEUROSCI.2001-12.2013

Hillman, H. (2000). Limitations of clinical and biological histology. Med. Hypotheses 54, 553-564. doi: 10.1054/mehy.1999.0894

Hirbec, H., Déglon, N., Foo, L. C., Goshen, I., Grutzendler, J., Hangen, E., et al. (2020). Emerging technologies to study glial cells. Glia 68, 1692-1728. doi: $10.1002 /$ glia. 23780

Hu, B.-Y., Du, Z.-W., Li, X.-J., Ayala, M., and Zhang, S.-C. (2009). Human oligodendrocytes from embryonic stem cells: conserved $\mathrm{SHH}$ signaling networks and divergent FGF effects. Development 136, 1443-1452. doi: 10.1242/dev.029447

Huang, W., Guo, Q., Bai, X., Scheller, A., and Kirchhoff, F. (2019). Early embryonic NG2 glia are exclusively gliogenic and do not generate neurons in the brain. Glia 67, 1094-1103. doi: 10.1002/glia.23590

Huang, W., Zhao, N., Bai, X., Karram, K., Trotter, J., Goebbels, S., et al. (2014). Novel NG2-CreERT2 knock-in mice demonstrate heterogeneous differentiation potential of NG2 glia during development. Glia 62, 896-913. doi: 10.1002/glia.22648

Hwang, B., Lee, J. H., and Bang, D. (2018). Single-cell RNA sequencing technologies and bioinformatics pipelines. Exp. Mol. Med. 50, 1-4. doi: 10.1038/s12276-018-0071-8

Ilyasov, A. A., Milligan, C. E., Pharr, E. P., and Howlett, A. C. (2018). The endocannabinoid system and oligodendrocytes in health and disease. Front. Neurosci. 12:733.doi: 10.3389/fnins.2018.00733

Irvine, K. A., and Blakemore, W. F. (2007). A different regional response by mouse oligodendrocyte progenitor cells (OPCs) to high-dose X-irradiation has consequences for repopulating OPC-depleted normal tissue. Eur. J. Neurosci. 25, 417-424. doi: 10.1111/j.1460-9568.2007.05313.x

Jackson, E. L., Garcia-Verdugo, J. M., Gil-Perotin, S., Roy, M., QuinonesHinojosa, A., Vandenberg, S., et al. (2006). PDGFR $\alpha$-positive B cells are neural stem cells in the adult SVZ that form glioma-like growths in response to increased PDGF signaling. Neuron 51, 187-199. doi: 10.1016/j.neuron.2006. 06.012 
Jacob, F., Salinas, R. D., Zhang, D. Y., Nguyen, P. T. T., Schnoll, J. G., Wong, S. Z. H., et al. (2020). A patient-derived glioblastoma organoid model and biobank recapitulates inter- and intra-tumoral heterogeneity. Cell 180, 188.e22-204.e22. doi: 10.1016/j.cell.2019.11.036

Kamimura, K., Suda, T., Zhang, G., and Liu, D. (2011). Advances in gene delivery systems. Pharmaceut. Med. 25, 293-306. doi: 10.2165/11594020-00000000000000

Kang, S. H., Fukaya, M., Yang, J. K., Rothstein, J. D., and Bergles, D. E. (2010). $\mathrm{NG}^{2+}$ CNS glial progenitors remain committed to the oligodendrocyte lineage in postnatal life and following neurodegeneration. Neuron 68, 668-681. doi: 10.1016/j.neuron.2010.09.009

Kashima, Y., Sakamoto, Y., Kaneko, K., Seki, M., Suzuki, Y., and Suzuki, A. (2020). Single-cell sequencing techniques from individual to multiomics analyses. Exp. Mol. Med. 52, 1419-1427. doi: 10.1038/s12276-020-00499-2

Kawabata, S., Takano, M., Numasawa-Kuroiwa, Y., Itakura, G., Kobayashi, Y., Nishiyama, Y., et al. (2016). Grafted human iPS cell-derived oligodendrocyte precursor cells contribute to robust remyelination of demyelinated axons after spinal cord injury. Stem Cell Rep. 6, 1-8. doi: 10.1016/j.stemcr.2015.11.013

Kayasandik, C. B., Ru, W., and Labate, D. (2020). A multistep deep learning framework for the automated detection and segmentation of astrocytes in fluorescent images of brain tissue. Sci. Rep. 10:5137. doi: 10.1038/s41598-02061953-9

Kessaris, N., Fogarty, M., Iannarelli, P., Grist, M., Wegner, M., and Richardson, W. D. (2006). Competing waves of oligodendrocytes in the forebrain and postnatal elimination of an embryonic lineage. Nat. Neurosci. 9, 173-179. doi: $10.1038 / \mathrm{nn} 1620$

Kikuchi, T., Gonzalez-Soriano, J., Kastanauskaite, A., Benavides-Piccione, R., Merchan-Perez, A., Defelipe, J., et al. (2020). Volume electron microscopy study of the relationship between synapses and astrocytes in the developing rat somatosensory cortex. Cereb. Cortex 30, 3800-3819. doi: $10.1093 /$ cercor/bhz343

Kim, D.-S., Jung, S. J., Lee, J. S., Lim, B. Y., Kim, H. A., Yoo, J.-E., et al. (2017). Rapid generation of OPC-like cells from human pluripotent stem cells for treating spinal cord injury. Exp. Mol. Med. 49:e361. doi: 10.1038/emm. 2017.106

Kishida, N., Maki, T., Takagi, Y., Yasuda, K., Kinoshita, H., Ayaki, T., et al. (2019). Role of perivascular oligodendrocyte precursor cells in angiogenesis after brain ischemia. J. Am. Heart Assoc. 8:e011824. doi: 10.1161/JAHA.118. 011824

Kroehne, V., Tsata, V., Marrone, L., Froeb, C., Reinhardt, S., Gompf, A., et al. (2017). Primary spinal OPC culture system from adult zebrafish to study oligodendrocyte differentiation in vitro. Front. Cell. Neurosci. 11:284. doi: $10.3389 /$ fncel.2017.00284

Kuhn, S., Gritti, L., Crooks, D., and Dombrowski, Y. (2019). Oligodendrocytes in development, myelin generation and beyond. Cells 8:1424. doi: 10.3390 /cells 8111424

Kukley, M., Kiladze, M., Tognatta, R., Hans, M., Swandulla, D., Schramm, J., et al. (2008). Glial cells are born with synapses. FASEB J. 22, 2957-2969. doi: 10.1096/fj.07-090985

Labrada-Moncada, F. E., Martínez-Torres, A., and Reyes-Haro, D. (2020). GABAA receptors are selectively expressed in NG2 glia of the cerebellar white matter. Neuroscience 433, 132-143. doi: 10.1016/j.neuroscience.2020.03.003

Lager, A. M., Corradin, O. G., Cregg, J. M., Elitt, M. S., Shick, H. E., Clayton, B. L. L., et al. (2018). Rapid functional genetics of the oligodendrocyte lineage using pluripotent stem cells. Nat. Commun. 9:3708. doi: 10.1038/s41467-018-06102-7

Lariosa-Willingham, K. D., Rosler, E. S., Tung, J. S., Dugas, J. C., Collins, T. L., and Leonoudakis, D. (2016). A high throughput drug screening assay to identify compounds that promote oligodendrocyte differentiation using acutely dissociated and purified oligodendrocyte precursor cells. BMC Res. Notes 9:419. doi: 10.1186/s13104-016-2220-2

Larson, V. A., Zhang, Y., and Bergles, D. E. (2016). Electrophysiological properties of $\mathrm{NG}^{+}$cells: matching physiological studies with gene expression profiles. Brain Res. 1638, 138-160. doi: 10.1016/j.brainres.2015.09.010

Lee, C., Lavoie, A., Liu, J., Chen, S. X., and Liu, B. H. (2020). Light up the brain: the application of optogenetics in cell-type specific dissection of mouse brain circuits. Front. Neural Circuits 14:18. doi: 10.3389/fncir.2020. 00018
Lentferink, D. H., Jongsma, J. M., Werkman, I., and Baron, W. (2018). Grey matter OPCs are less mature and less sensitive to IFN $\gamma$ than white matter OPCs: consequences for remyelination. Sci. Rep. 8:2113. doi: 10.1038/s41598018-19934-6

Levine, J. M., Reynolds, R., and Fawcett, J. W. (2001). The oligodendrocyte precursor cell in health and disease. Trends Neurosci. 24, 39-47. doi: 10.1016/s0166-2236(00)01691-x

Li, L., Tian, E., Chen, X., Chao, J., Klein, J., Qu, Q., et al. (2018). GFAP mutations in astrocytes impair oligodendrocyte progenitor proliferation and myelination in an hiPSC model of alexander disease. Cell Stem Cell 23, 239.e6-251.e6. doi: $10.1016 /$ j.stem.2018.07.009

Lin, S.-C., and Bergles, D. E. (2004). Synaptic signaling between GABAergic interneurons and oligodendrocyte precursor cells in the hippocampus. Nat. Neurosci. 7, 24-32. doi: 10.1038/nn1162

Lin, G., Mela, A., Guilfoyle, E. M., and Goldman, J. E. (2009). Neonatal and adult $\mathrm{O}^{+}{ }^{+}$oligodendrocyte lineage cells display different growth factor responses and different gene expression patterns. J. Neurosci. Res. 87, 3390-3402. doi: 10.1002/jnr.22065

Liu, Y., and Aguzzi, A. (2020). NG2 glia are required for maintaining microglia homeostatic state. Glia 68, 345-355. doi: 10.1002/glia.23721

Lopez-Caraballo, L., Martorell-Marugan, J., Carmona-Sáez, P., and GonzalezMunoz, E. (2020). iPS-derived early oligodendrocyte progenitor cells from SPMS patients reveal deficient in vitro cell migration stimulation. Cells 9:1803. doi: $10.3390 /$ cells 9081803

Luckner, M., Burgold, S., Filser, S., Scheungrab, M., Niyaz, Y., Hummel, E., et al. (2018). Label-free 3D-CLEM using endogenous tissue landmarks. iScience 6, 92-101. doi: 10.1016/j.isci.2018.07.012

Madhavan, M., Nevin, Z. S., Shick, H. E., Garrison, E., Clarkson-Paredes, C., Karl, M., et al. (2018). Induction of myelinating oligodendrocytes in human cortical spheroids. Nat. Methods 15, 700-706. doi: 10.1038/s41592-018-0081-4

Maki, T., Maeda, M., Uemura, M., Lo, E. K., Terasaki, Y., Liang, A. C., et al. (2015). Potential interactions between pericytes and oligodendrocyte precursor cells in perivascular regions of cerebral white matter. Neurosci. Lett. 597, 164-169. doi: 10.1016/j.neulet.2015.04.047

Marie, C., Clavairoly, A., Frah, M., Hmidan, H., Yan, J., Zhao, C., et al. (2018). Oligodendrocyte precursor survival and differentiation requires chromatin remodeling by Chd7 and Chd8. Proc. Natl. Acad. Sci. U S A 115:E8246. doi: $10.1073 /$ pnas. 1802620115

Marisca, R., Hoche, T., Agirre, E., Hoodless, L. J., Barkey, W., Auer, F., et al. (2020). Functionally distinct subgroups of oligodendrocyte precursor cells integrate neural activity and execute myelin formation. Nat. Neurosci. 23, 363-374. doi: 10.1038/s41593-019-0581-2

Marques, S., Van Bruggen, D., Vanichkina, D. P., Floriddia, E. M., Munguba, H., Varemo, L., et al. (2018). Transcriptional convergence of oligodendrocyte lineage progenitors during development. Dev. Cell 46, 504.e7-517.e7. doi: 10.1016/j.devcel.2018.07.005

Marques, S., Zeisel, A., Codeluppi, S., van Bruggen, D., Mendanha Falcao, A., Xiao, L., et al. (2016). Oligodendrocyte heterogeneity in the mouse juvenile and adult central nervous system. Science 352, 1326-1329. doi: 10.1126/science. aaf6463

Marsters, C. M., Nesan, D., Far, R., Klenin, N., Pittman, Q. J., and Kurrasch, D. M. (2020). Embryonic microglia influence developing hypothalamic glial populations. J. Neuroinflammation 17:146. doi: 10.1186/s12974-020-01811-7

Marton, R. M., Miura, Y., Sloan, S. A., Li, Q., Revah, O., Levy, R. J., et al. (2019). Differentiation and maturation of oligodendrocytes in human threedimensional neural cultures. Nat. Neurosci. 22, 484-491. doi: 10.1038/s41593018-0316-9

Mason, J. L., and Goldman, J. E. (2002). A2B5+ and O4+ Cycling progenitors in the adult forebrain white matter respond differentially to PDGF-AA, FGF-2, and IGF-1. Mol. Cell. Neurosci. 20, 30-42. doi: 10.1006/mcne.2002.1114

Matjusaitis, M., Wagstaff, L. J., Martella, A., Baranowski, B., Blin, C., Gogolok, S., et al. (2019). Reprogramming of fibroblasts to oligodendrocyte progenitor-like cells using CRISPR/Cas9-based synthetic transcription factors. Stem Cell Rep. 13, 1053-1067. doi: 10.1016/j.stemcr.2019.10.010

Mecha, M., Yanguas-Casés, N., Feliú, A., Mestre, L., Carrillo-Salinas, F. J., Riecken, K., et al. (2020). Involvement of Wnt7a in the role of M2c microglia in neural stem cell oligodendrogenesis. J. Neuroinflammation 17:88. doi: 10.1186/s12974-020-01734-3 
Medina-Rodríguez, E. M., Arenzana, F. J., Bribián, A., and De Castro, F. (2013). Protocol to isolate a large amount of functional oligodendrocyte precursor cells from the cerebral cortex of adult mice and humans. PLoS One 8:e81620. doi: 10.1371/journal.pone.0081620

Melissaridou, S., Wiechec, E., Magan, M., Jain, M. V., Chung, M. K., Farnebo, L., et al. (2019). The effect of $2 \mathrm{D}$ and $3 \mathrm{D}$ cell cultures on treatment response, EMT profile and stem cell features in head and neck cancer. Cancer Cell Int. 19:16. doi: 10.1186/s12935-019-0733-1

Min, K., Cho, I., Choi, M., and Chang, J.-B. (2020). Multiplexed expansion microscopy of the brain through fluorophore screening. Methods 174, 3-10. doi: 10.1016/j.ymeth.2019.07.017

Morales Pantoja, I. E., Smith, M. D., Rajbhandari, L., Cheng, L., Gao, Y., Mahairaki, V., et al. (2020). iPSCs from people with MS can differentiate into oligodendrocytes in a homeostatic but not an inflammatory milieu. PLoS One 15:e0233980. doi: 10.1371/journal.pone.0233980

Moshrefi-Ravasdjani, B., Dublin, P., Seifert, G., Jennissen, K., Steinhauser, C., Kafitz, K. W., et al. (2017). Changes in the proliferative capacity of NG2 cell subpopulations during postnatal development of the mouse hippocampus. Brain Struct. Funct. 222, 831-847. doi: 10.1007/s00429-016-1249-2

Mount, C. W., Yalçin, B., Cunliffe-Koehler, K., Sundaresh, S., and Monje, M. (2019). Monosynaptic tracing maps brain-wide afferent oligodendrocyte precursor cell connectivity. eLife 8:e49291. doi: 10.7554/eLife.49291

Moyon, S., Dubessy, A. L., Aigrot, M. S., Trotter, M., Huang, J. K., Dauphinot, L., et al. (2015). Demyelination causes adult CNS progenitors to revert to an immature state and express immune cues that support their migration. J. Neurosci. 35, 4-20. doi: 10.1523/JNEUROSCI.0849-14.2015

Nagy, B., Hovhannisyan, A., Barzan, R., Chen, T. J., and Kukley, M. (2017). Different patterns of neuronal activity trigger distinct responses of oligodendrocyte precursor cells in the corpus callosum. PLoS Biol. 15:e2001993. doi: 10.1371/journal.pbio.2001993

Najm, F. J., Zaremba, A., Caprariello, A. V., Nayak, S., Freundt, E. C., Scacheri, P. C., et al. (2011). Rapid and robust generation of functional oligodendrocyte progenitor cells from epiblast stem cells. Nat. Methods 8, 957-962. doi: 10.1038/nmeth.1712

Nakano, M., Tamura, Y., Yamato, M., Kume, S., Eguchi, A., Takata, K., et al. (2017). NG2 glial cells regulate neuroimmunological responses to maintain neuronal function and survival. Sci. Rep. 7:42041. doi: 10.1038/srep 42041

Nevin, Z. S., Factor, D. C., Karl, R. T., Douvaras, P., Laukka, J., Windrem, M. S., et al. (2017). Modeling the mutational and phenotypic landscapes of pelizaeusmerzbacher disease with human iPSC-derived oligodendrocytes. Am. J. Hum. Genet. 100, 617-634. doi: 10.1016/j.ajhg.2017.03.005

Ng, A. H. M., Khoshakhlagh, P., Rojo Arias, J. E., Pasquini, G., Wang, K., Swiersy, A., et al. (2020). A comprehensive library of human transcription factors for cell fate engineering. Nat. Biotechnol. doi: 10.1038/s41587-020-07426 [Epub ahead of print].

Nicaise, A. M., Wagstaff, L. J., Willis, C. M., Paisie, C., Chandok, H., Robson, P., et al. (2019). Cellular senescence in progenitor cells contributes to diminished remyelination potential in progressive multiple sclerosis. Proc. Natl. Acad. Sci. U S A 116, 9030-9039. doi: 10.1073/pnas.1818348116

Nikolakopoulou, A. M., Montagne, A., Kisler, K., Dai, Z., Wang, Y., Huuskonen, M. T., et al. (2019). Pericyte loss leads to circulatory failure and pleiotrophin depletion causing neuron loss. Nat. Neurosci. 22, 1089-1098. doi: 10.1038/s41593-019-0434-Z

Nutma, E., van Gent, D., Amor, S., and Peferoen, L. A. N. (2020). Astrocyte and oligodendrocyte cross-talk in the central nervous system. Cells 9:600. doi: $10.3390 /$ cells 9030600

Ogawa, J., Pao, G. M., Shokhirev, M. N., and Verma, I. M. (2018). Glioblastoma model using human cerebral organoids. Cell Rep. 23, 1220-1229. doi: 10.1016/j. celrep.2018.03.105

Oh, S. W., Harris, J. A., Ng, L., Winslow, B., Cain, N., Mihalas, S., et al. (2014). A mesoscale connectome of the mouse brain. Nature 508, 207-214. doi: $10.1038 /$ nature 13186

O'Meara, R. W., Ryan, S. D., Colognato, H., and Kothary, R. (2011). Derivation of enriched oligodendrocyte cultures and oligodendrocyte/neuron myelinating co-cultures from post-natal murine tissues. J. Vis. Exp. 54:3324. doi: $10.3791 / 3324$
Ono, K., Kagawa, T., Tsumori, T., Yokota, S., and Yasui, Y. (2001). Morphological changes and cellular dynamics of oligodendrocyte lineage cells in the developing vertebrate central nervous system. Dev. Neurosci. 23, 346-355. doi: $10.1159 / 000048718$

Ortolani, D., Manot-Saillet, B., Orduz, D., Ortiz, F. C., and Angulo, M. C. (2018). in vivo optogenetic approach to study neuron-oligodendroglia interactions in mouse pups. Front. Cell. Neurosci. 12:477. doi: 10.3389/fncel.2018.00477

Ozerdem, U., Grako, K. A., Dahlin-Huppe, K., Monosov, E., and Stallcup, W. B. (2001). NG2 proteoglycan is expressed exclusively by mural cells during vascular morphogenesis. Dev. Dyn. 222, 218-227. doi: 10.1002/dvdy.1200

Paez, P. M., Fulton, D. J., Spreuer, V., Handley, V., Campagnoni, C. W., Macklin, W. B., et al. (2009). Golli myelin basic proteins regulate oligodendroglial progenitor cell migration through voltage-gated $\mathrm{Ca}^{2+}$ influx. J. Neurosci. 29, 6663-6676. doi: 10.1523/JNEUROSCI.5806-08.2009

Pang, Y., Simpson, K., Miguel-Hidalgo, J. J., and Savich, R. (2018). Neuron/oligodendrocyte myelination coculture. Methods Mol. Biol. 1791, 131-144. doi: 10.1007/978-1-4939-7862-5_10

Pawlowski, M., Ortmann, D., Bertero, A., Tavares, J. M., Pedersen, R. A., Vallier, L., et al. (2017). Inducible and deterministic forward programming of human pluripotent stem cells into neurons, skeletal myocytes, and oligodendrocytes. Stem Cell Rep. 8, 803-812. doi: 10.1016/j.stemcr.2017. 02.016

Pedraza, C. E., Monk, R., Lei, J., Hao, Q., and Macklin, W. B. (2008). Production, characterization, and efficient transfection of highly pure oligodendrocyte precursor cultures from mouse embryonic neural progenitors. Glia 56, 1339-1352. doi: 10.1002/glia.20702

Perlman, K., Couturier, C. P., Yaqubi, M., Tanti, A., Cui, Q. L., Pernin, F., et al. (2020). Developmental trajectory of oligodendrocyte progenitor cells in the human brain revealed by single cell RNA sequencing. Glia 68, 1291-1303. doi: 10.1002/glia.23777

Pitman, K. A., Ricci, R., Gasperini, R., Beasley, S., Pavez, M., Charlesworth, J., et al. (2020). The voltage-gated calcium channel CaV1.2 promotes adult oligodendrocyte progenitor cell survival in the mouse corpus callosum but not motor cortex. Glia 68, 376-392. doi: 10.1002/glia.23723

Purger, D., Gibson, E. M., and Monje, M. (2016). Myelin plasticity in the central nervous system. Neuropharmacology 110, 563-573. doi: 10.1016/j.neuropharm. 2015.08.001

Rivers, L. E., Young, K. M., Rizzi, M., Jamen, F., Psachoulia, K., Wade, A., et al. (2008). PDGFRA/NG2 glia generate myelinating oligodendrocytes and piriform projection neurons in adult mice. Nat. Neurosci. 11, 1392-1401. doi: $10.1038 / \mathrm{nn} .2220$

Robins, S. C., Trudel, E., Rotondi, O., Liu, X., Djogo, T., Kryzskaya, D., et al. (2013). Evidence for NG2-glia derived, adult-born functional neurons in the hypothalamus. PLoS One 8:e78236. doi: 10.1371/journal.pone. 0078236

Rodrigues, G. M. C., Gaj, T., Adil, M. M., Wahba, J., Rao, A. T., Lorbeer, F. K., et al. (2017). Defined and scalable differentiation of human oligodendrocyte precursors from pluripotent stem cells in a 3D culture system. Stem Cell Rep. 8, 1770-1783. doi: 10.1016/j.stemcr.2017.04.027

Rui, Y., Pollitt, S. L., Myers, K. R., Feng, Y., and Zheng, J. Q. (2020). Spontaneous local calcium transients regulate oligodendrocyte development in culture through store operated $\mathrm{Ca}^{2+}$ entry and release. eNeuro 4:ENEURO.034719.2020. doi: 10.1523/ENEURO.0347-19.2020

Ruiz-Garcia, H., Alvarado-Estrada, K., Schiapparelli, P., Quinones-Hinojosa, A., and Trifiletti, D. M. (2020). Engineering three-dimensional tumor models to study glioma cancer stem cells and tumor microenvironment. Front. Cell. Neurosci. 14:558381. doi: 10.3389/fncel.2020.558381

Sakry, D., Neitz, A., Singh, J., Frischknecht, R., Marongiu, D., Biname, F., et al. (2014). Oligodendrocyte precursor cells modulate the neuronal network by activity-dependent ectodomain cleavage of glial NG2. PLoS Biol. 12:e1001993. doi: 10.1371/journal.pbio.1001993

Sakry, D., Yigit, H., Dimou, L., and Trotter, J. (2015). Oligodendrocyte precursor cells synthesize neuromodulatory factors. PLoS One 10:e0127222. doi: 10.1371/journal.pone.0127222

Samudyata, Castelo-Branco, G., and Liu, J. (2020). Epigenetic regulation of oligodendrocyte differentiation: from development to demyelinating disorders. Glia 68, 1619-1630. doi: 10.1002/glia.23820 
Santiago González, D. A., Cheli, V. T., Zamora, N. N., Lama, T. N., Spreuer, V., Murphy, G. G., et al. (2017). Conditional deletion of the L-type calcium channel Cav1.2 in NG2-positive cells impairs remyelination in mice. J. Neurosci. 37, 10038-10051. doi: 10.1523/JNEUROSCI.1787-17.2017

Schertel, A., Snaidero, N., Han, H.-M., Ruhwedel, T., Laue, M., Grabenbauer, M., et al. (2013). Cryo FIB-SEM: Volume imaging of cellular ultrastructure in native frozen specimens. J. Struct. Biol. 184, 355-360. doi: 10.1016/j.jsb.2013. 09.024

Schoor, C., Brocke-Ahmadinejad, N., Gieselmann, V., and Winter, D. (2019). Investigation of oligodendrocyte precursor cell differentiation by quantitative proteomics. Proteomics 19:e1900057. doi: 10.1002/pmic.2019 00057

Seo, J. H., Maki, T., Maeda, M., Miyamoto, N., Liang, A. C., Hayakawa, K., et al. (2014). Oligodendrocyte precursor cells support blood-brain barrier integrity via TGF- $\beta$ signaling. PLoS One 9:e103174. doi: 10.1371/journal.pone. 0103174

Seo, J. H., Miyamoto, N., Hayakawa, K., Pham, L. D., Maki, T., Ayata, C., et al. (2013). Oligodendrocyte precursors induce early blood-brain barrier opening after white matter injury. J. Clin. Invest. 123, 782-786. doi: 10.1172/ JCI65863

Serwanski, D. R., Jukkola, P., and Nishiyama, A. (2017). Heterogeneity of astrocyte and NG2 cell insertion at the node of ranvier. J. Comp. Neurol. 525, 535-552. doi: $10.1002 / \mathrm{cne} .24083$

Spitzer, S. O., Sitnikov, S., Kamen, Y., Evans, K. A., Kronenberg-Versteeg, D., Dietmann, S., et al. (2019). Oligodendrocyte progenitor cells become regionally diverse and heterogeneous with age. Neuron 101, 459.e5-471.e5. doi: 10.1016/j. neuron.2018.12.020

Ståhl, P. L., Salmén, F., Vickovic, S., Lundmark, A., Navarro, J. F., Magnusson, J., et al. (2016). Visualization and analysis of gene expression in tissue sections by spatial transcriptomics. Science 353, 78-82. doi: 10.1126/science. aaf2403

Sung, H.-Y., Chen, W.-Y., Huang, H.-T., Wang, C.-Y., Chang, S.-B., and Tzeng, S.-F. (2019). Down-regulation of interleukin-33 expression in oligodendrocyte precursor cells impairs oligodendrocyte lineage progression. J. Neurochem. 150, 691-708. doi: 10.1111/jnc.14788

Tasic, B., Menon, V., Nguyen, T. N., Kim, T. K., Jarsky, T., Yao, Z., et al. (2016). Adult mouse cortical cell taxonomy revealed by single cell transcriptomics. Nat. Neurosci. 19, 335-346. doi: 10.1038/nn.4216

Traiffort, E., Zakaria, M., Laouarem, Y., and Ferent, J. (2016). Hedgehog: a key signaling in the development of the oligodendrocyte lineage. J. Dev. Biol. 4:28. doi: $10.3390 / \mathrm{jdb} 4030028$

Tsien, R. Y. (1980). New calcium indicators and buffers with high selectivity against magnesium and protons: design, synthesis, and properties of prototype structures. Biochemistry 19, 2396-2404. doi: 10.1021/bi00552a018

Tsien, R. Y. (1989). Fluorescent indicators of ion concentrations. Methods Cell Biol. 30, 127-156. doi: 10.1016/s0091-679x(08)60978-4

Valério-Gomes, B., Guimarães, D. M., Szczupak, D., and Lent, R. (2018). The absolute number of oligodendrocytes in the adult mouse brain. Front. Neuroanat. 12:90. doi: 10.3389/fnana.2018.00090

Vélez-Fort, M., Maldonado, P. P., Butt, A. M., Audinat, E., and Angulo, M. C. (2010). Postnatal switch from synaptic to extrasynaptic transmission between interneurons and NG2 cells. J. Neurosci. 30, 6921-6929. doi: 10.1523/JNEUROSCI.0238-10.2010

Vidova, V., and Spacil, Z. (2017). A review on mass spectrometry-based quantitative proteomics: targeted and data independent acquisition. Anal. Chim. Acta 964, 7-23. doi: 10.1016/j.aca.2017.01.059

Vitry, S., Avellana-Adalid, V., Hardy, R., Lachapelle, F., and Baron-Van Evercooren, A. (1999). Mouse oligospheres: from pre-progenitors to functional oligodendrocytes. J. Neurosci. Res. 58, 735-751. doi: 10.1002/(sici)10974547(19991215)58:6<735::aid-jnr2 >3.0.co;2-9

Vogel, S., Schäfer, C., Hess, S., Folz-Donahue, K., Nelles, M., Minassian, A., et al. (2019). The in vivo timeline of differentiation of engrafted human neural progenitor cells. Stem Cell Res. 37:101429. doi: 10.1016/j.scr.2019. 101429

Wan, R., Cheli, V. T., Santiago-Gonzalez, D. A., Rosenblum, S. L., Wan, Q., and Paez, P. M. (2020). Impaired postnatal myelination in a conditional knockout mouse for the ferritin heavy chain in oligodendroglial cells. J. Neurosci. 40, 7609-7624. doi: 10.1523/JNEUROSCI.1281-20.2020
Wang, Y., Ali, M., Wang, Y., Kucenas, S., and Yu, G. (2018). Detection and tracking of migrating oligodendrocyte progenitor cells from in vivo fluorescence time-lapse imaging data. Proc. IEEE Int. Symp. Biomed. Imaging 2018, 961-964. doi: 10.1109/ISBI.2018.8363730

Wang, S., Bates, J., Li, X., Schanz, S., Chandler-Militello, D., Levine, C., et al. (2013). Human iPSC-derived oligodendrocyte progenitor cells can myelinate and rescue a mouse model of congenital hypomyelination. Cell Stem Cell 12, 252-264. doi: 10.1016/j.stem.2012.12.002

Wang, S., and Young, K. M. (2014). White matter plasticity in adulthood. Neuroscience 276, 148-160. doi: 10.1016/j.neuroscience.2013.10.018

Wassie, A. T., Zhao, Y., and Boyden, E. S. (2019). Expansion microscopy: principles and uses in biological research. Nat. Methods 16, 33-41. doi: 10.1038/s41592-018-0219-4

Watanabe, T., Frahm, J., and Michaelis, T. (2016). In vivo brain MR imaging at subnanoliter resolution: contrast and histology. Magn. Reson. Med. Sci. 15, 11-25. doi: 10.2463/mrms.2015-0048

Weil, M.-T., Heibeck, S., Töpperwien, M., Tom Dieck, S., Ruhwedel, T., Salditt, T., et al. (2018). Axonal ensheathment in the nervous system of lamprey: implications for the evolution of myelinating glia. J. Neurosci. 38, 6586-6596. doi: 10.1523/JNEUROSCI.1034-18.2018

Wen, S., Ma, D., Zhao, M., Xie, L., Wu, Q., Gou, L., et al. (2020). Spatiotemporal single-cell analysis of gene expression in the mouse suprachiasmatic nucleus. Nat. Neurosci. 23, 456-467. doi: 10.1038/s41593-020-0586-x

Willems, J., de Jong, A. P. H., Scheefhals, N., Mertens, E., Catsburg, L. A. E., Poorthuis, R. B., et al. (2020). ORANGE: a CRISPR/Cas9-based genome editing toolbox for epitope tagging of endogenous proteins in neurons. PLoS Biol. 18:e3000665. doi: 10.1371/journal.pbio.3000665

Woodruff, R. H., Fruttiger, M., Richardson, W. D., and Franklin, R. J. (2004). Platelet-derived growth factor regulates oligodendrocyte progenitor numbers in adult CNS and their response following CNS demyelination. Mol. Cell. Neurosci. 25, 252-262. doi: 10.1016/j.mcn.2003.10.014

Yamada, M., Nagasaki, S. C., Ozawa, T., and Imayoshi, I. (2020). Light-mediated control of Gene expression in mammalian cells. Neurosci. Res. 152, 66-77. doi: 10.1016/j.neures.2019.12.018

Yamashita, T., Miyamoto, Y., Bando, Y., Ono, T., Kobayashi, S., Doi, A., et al. (2017). Differentiation of oligodendrocyte progenitor cells from dissociated monolayer and feeder-free cultured pluripotent stem cells. PLoS One 12, e0171947-e0171947. doi: 10.1371/journal.pone.0171947

Yang, J., Cheng, X., Shen, J., Xie, B., Zhao, X., Zhang, Z., et al. (2016). A novel approach for amplification and purification of mouse oligodendrocyte progenitor cells. Front. Cell. Neurosci. 10:203. doi: 10.3389/fncel.2016. 00203

Yu, T., Qi, Y., Gong, H., Luo, Q., and Zhu, D. (2018). Optical clearing for multiscale biological tissues. J. Biophotonics 11:e201700187. doi: 10.1002/jbio.2017 00187

Zeisel, A., Muñoz-Manchado, A. B., Codeluppi, S., Lönnerberg, P., La Manno, G., Juréus, A., et al. (2015). Brain structure. Cell types in the mouse cortex and hippocampus revealed by single-cell RNA-seq. Science 347, 1138-1142. doi: 10.1126/science.aaa1934

Zhang, Y., Chen, K., Sloan, S. A., Bennett, M. L., Scholze, A. R., O'Keeffe, S., et al. (2014). An RNA-sequencing transcriptome and splicing database of glia, neurons and vascular cells of the cerebral cortex. J. Neurosci. 34, 11929-11947. doi: 10.1523/JNEUROSCI.1860-14.2014

Zhang, M., Liu, Y., Wu, S., and Zhao, X. (2019). $\mathrm{Ca}^{2+}$ signaling in oligodendrocyte development. Cell. Mol. Neurobiol. 39, 1071-1080. doi: 10.1007/s10571-01900705-4

Zhang, S.-Z., Wang, Q.-Q., Yang, Q.-Q., Gu, H.-Y., Yin, Y.-Q., Li, Y.-D., et al. (2019). NG2 glia regulate brain innate immunity via TGF- $\beta 2 / T G F B R 2$ axis. BMC Med. 17:204. doi: 10.1186/s12916-019-1439-x

Zhou, W., Ge, W.-P., Zeng, S., Duan, S., and Luo, Q. (2007). Identification and two-photon imaging of oligodendrocyte in $\mathrm{CA} 1$ region of hippocampal slices. Biochem. Biophys. Res. Commun. 352, 598-602. doi: 10.1016/j.bbrc.2006.11.048

Zhu, X., Bergles, D. E., and Nishiyama, A. (2008a). NG2 cells generate both oligodendrocytes and gray matter astrocytes. Development 135, 145-157. doi: $10.1242 / \mathrm{dev} .004895$

Zhu, X., Hill, R. A., and Nishiyama, A. (2008b). NG2 cells generate oligodendrocytes and gray matter astrocytes in the spinal cord. Neuron Glia Biol. 4, 19-26. doi: 10.1017/S1740925X09000015 
Zhu, X., Hill, R. A., Dietrich, D., Komitova, M., Suzuki, R., and Nishiyama, A. (2011). Age-dependent fate and lineage restriction of single NG2 cells. Development 138, 745-753. doi: 10.1242/dev.047951

Zhu, X., Huang, L., Zheng, Y., Song, Y., Xu, Q., Wang, J., et al. (2019). Ultrafast optical clearing method for three-dimensional imaging with cellular resolution. Proc. Natl. Acad. Sci. U S A 116, 11480-11489. doi: 10.1073/pnas.18195 83116

Zong, H., Parada, L. F., and Baker, S. J. (2015). Cell of origin for malignant gliomas and its implication in therapeutic development. Cold Spring Harb. Perspect. Biol. 7:a020610. doi: 10.1101/cshperspect.a0 20610
Conflict of Interest: The authors declare that the research was conducted in the absence of any commercial or financial relationships that could be construed as a potential conflict of interest.

Copyright (C) 2021 Galichet, Clayton and Lovell-Badge. This is an open-access article distributed under the terms of the Creative Commons Attribution License (CC BY). The use, distribution or reproduction in other forums is permitted, provided the original author(s) and the copyright owner(s) are credited and that the original publication in this journal is cited, in accordance with accepted academic practice. No use, distribution or reproduction is permitted which does not comply with these terms. 